Review Article

\title{
Review of the Evolution of Mining-Induced Stress and the Failure Characteristics of Surrounding Rock Based on Microseismic Tomography
}

\author{
Qiankun Zhu, ${ }^{1,2}$ Xingdong Zhao ${ }^{\mathbb{D}},{ }^{1}$ and Erik Westman ${ }^{2}$ \\ ${ }^{1}$ Department of Mining Engineering, Northeastern University, Shenyang 110819, China \\ ${ }^{2}$ Department of Mining and Minerals Engineering, Virginia Tech, Blacksburg, VA 24061, USA \\ Correspondence should be addressed to Xingdong Zhao; zhaoxingdong@mail.neu.edu.cn
}

Received 20 July 2021; Accepted 26 August 2021; Published 16 September 2021

Academic Editor: Xuesheng Liu

Copyright ( 2021 Qiankun Zhu et al. This is an open access article distributed under the Creative Commons Attribution License, which permits unrestricted use, distribution, and reproduction in any medium, provided the original work is properly cited.

With the gradual depletion of shallow resources, deep mining has become an inevitable trend and has become an important part of the world mining industry. The high stress concentration caused by redistribution of original stress field will lead to stress-driven failure of surrounding rock; conventional methods, such as point-location stress measurement, analytical analysis, numerical simulation, and physical modeling, are not able to completely reflect the distribution and evolution characteristics of the mininginduced stress field in real time and at mine scale, so it is difficult to fully understand, control, and prevent mining-induced injuries and fatalities. In the past decades, microseismic monitoring technology, velocity tomography, numerical simulation, and laboratory test technology have been successfully applied to better understand mining-induced stress and rock mass failures. The combination of these methods has led to innovative ways to investigate the mining-induced stress field, surrounding rock failure, and hazard prevention. This review focuses on the mining-induced stress and velocity tomography based on microseismic monitoring data. Research progress in analysis and measurement methods of mining-induced stress, rock mechanics for mining, and velocity tomography practices are presented.

\section{Introduction}

With the development and utilization of shallow mineral resources, resulting in the decrease of shallow mineral resources year by year, the mining of resources is in the stage of comprehensively advancing to greater depths. There are many mines with a depth of more than $1000 \mathrm{~m}$, mostly distributed in South Africa and Canada, but also in the United States, India, Australia, Russia, Poland, Spain, Zambia, and other regions [1-3]. The depth of most gold mines in South Africa is more than $2000 \mathrm{~m}$, among which the depth of the Mponeng Gold Mine is $4350 \mathrm{~m}$, and the deepest end of the ore body is more than $7500 \mathrm{~m}$. The mining depths of Savuka and Tautona are more than $3700 \mathrm{~m}$, the West Deep gold mine of Anglo Gold Co., Ltd., has a depth of $3700 \mathrm{~m}$, the ore body of West Driefontein gold mine occurs in the underground of $600 \mathrm{~m}$ and extends to below $6000 \mathrm{~m}$.
At present, the deepest South Deep Level gold mine has a mining depth of $3500 \mathrm{~m}$. The Creighton Mine in Sudbury, Ontario, Canada, has a mining depth of $2420 \mathrm{~m}$, and the Kidd copper zinc mine in Timmins has a mining depth of $2926 \mathrm{~m}$. In the Kolar Gold Fields of India, there are 3 gold mines with a mining depth of more than $2400 \mathrm{~m}$, of which the depth of the Champion Reef Gold Mine is up to $3260 \mathrm{~m}$. In the Kryvyi Rih iron mine area of Ukraine, there are 8 mines with a development depth of $1570 \mathrm{~m}$, including Jerrensky, Kirov, and Comintern, and it is expected to reach $2000-2500 \mathrm{~m}$ in the future. The mining depth of the Lucky Friday Mine in the US is $2600 \mathrm{~m}$. In addition, the mining depth of some nonferrous metal mines in China, Australia, Poland, Brazil, etc., also exceeds $1000 \mathrm{~m}$. The depths of 23 deepest mines around the globe are shown in Figure 1.

The notable difference between deep mining and shallow mining lies in the special engineering environment of deep 


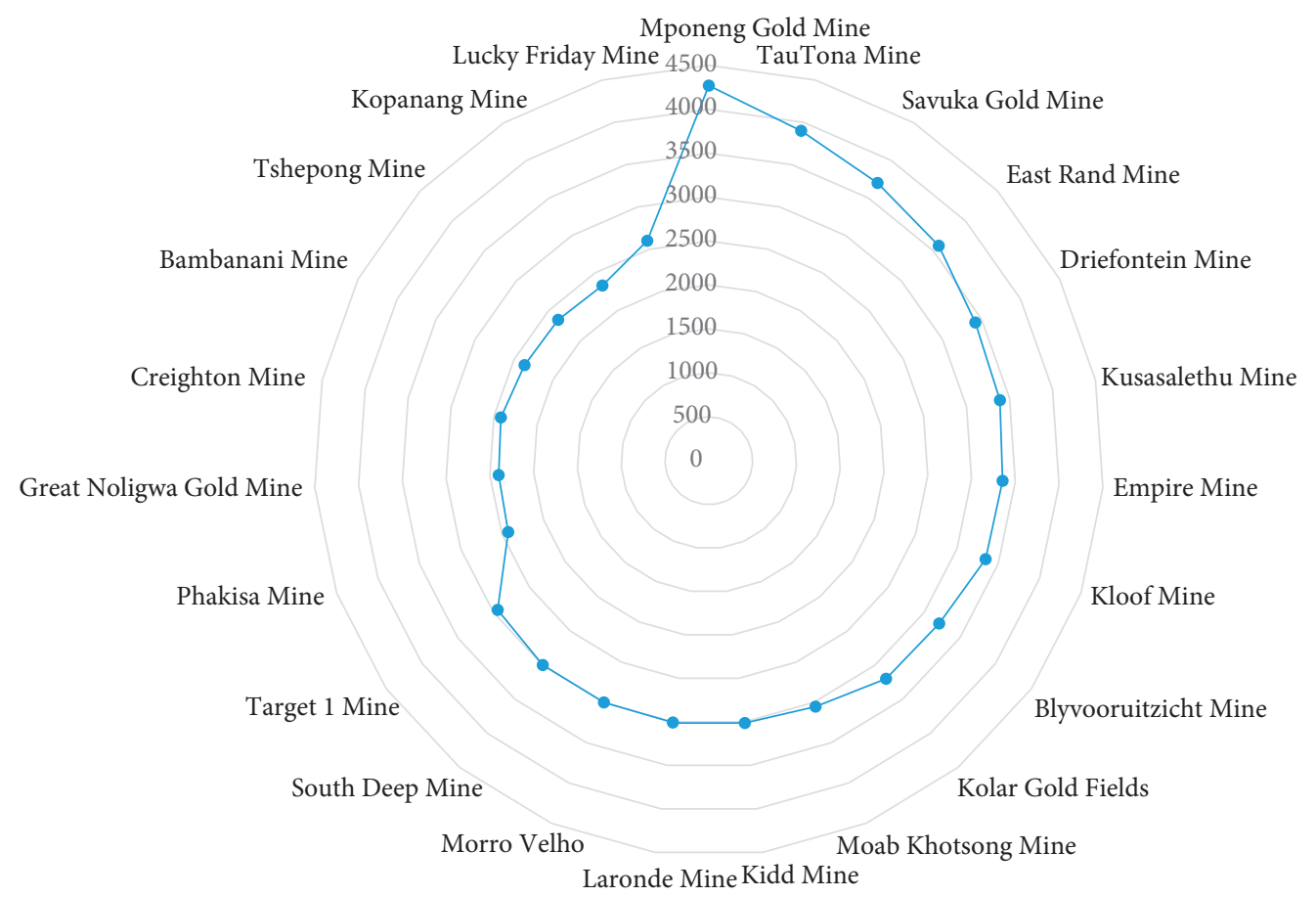

Figure 1: Typical deep mining mines in the world.

mining. Under the complex environment of "high in situ stress, high temperature, high water pressure, and mining disturbance," the structure, basic physical and mechanical characteristics, and engineering response of the deep rock mass are fundamentally different than that at more shallow depths, as shown in Figure 2. The mechanical characteristics of the dynamic-static combination of rock mass, brittleductile transformation, creep of hard rock, and large deformation are due to the sudden change in dynamic response process. Moreover, the mining-induced stress in deep mining has a significant effect on unexpected failures which result in injuries and fatalities. With the increase of mining depth year by year, the hazards caused by mininginduced stress become more and more prominent.

This paper summarizes the research progress in understanding mining-induced stress, rock mechanics related with mining disturbance, and microseismic velocity tomography and its application in mining engineering. The aim of this review is to build the relationships among three topics: mining-induced stress, rock mass response, and microseismic velocity tomography; each topic is reviewed in a separate section. In Section 2, the developments in mininginduced stress are summarized, with the focus on stress evolution characteristics and measurement methods. In Section 3, we give a brief summary of the failure and deformation characteristics under the influence of mining disturbance. In Section 4, we summarize the microseismic and velocity tomography technology and their application in mining engineering, with the focus on the velocity and stress relation, theory of seismic velocity tomography and their application in stress state imaging, hazard assessment, rock mass characterization, and geology structure detection. At the same time, this paper points out the limitation of current microseismic tomography methods and applications and puts forward some suggestions for the future research trend.

\section{Mining-Induced Stress}

Mining-induced stress refers to the redistribution of stress induced by mining activities under the influence of the in situ stress field. The formation of mining-induced stress is based on the in situ stress and mining activities; that is to say, the mining-induced stress acts on the surrounding rock mass of the stopes (roadways, shafts, etc.), causing various types of damage to the surrounding rock mass and mine openings [5]. Three principal stresses $\left(\sigma_{1}, \sigma_{2}\right.$, and $\left.\sigma_{3}\right)$ induced in an element of rock are shown in Figure 3. In a deep longwall panel of an underground coal mine, there are zones around the longwall panel or in pillars, where the vertical stress exceeds the average overburden pressure before mining [6]. The above-average pressure is called the abutment pressure, which can be divided into the front abutment load and the side abutment load (Figure 4). To estimate the induced stress more accurately, the in situ stresses should be determined before mining.

2.1. Evolution Characteristics of Mining-Induced Stress. The mining-induced stress field has a certain spatial distribution range, and its magnitude and orientation change with the development of mining activities and time. The distribution, magnitude, and orientation of mining-induced stress are related with support method, panel shape, in situ stress, physical and mechanical properties of rock mass, mining methods, mining sequence, structure and quality of rock mass, engineering geological conditions, and time 


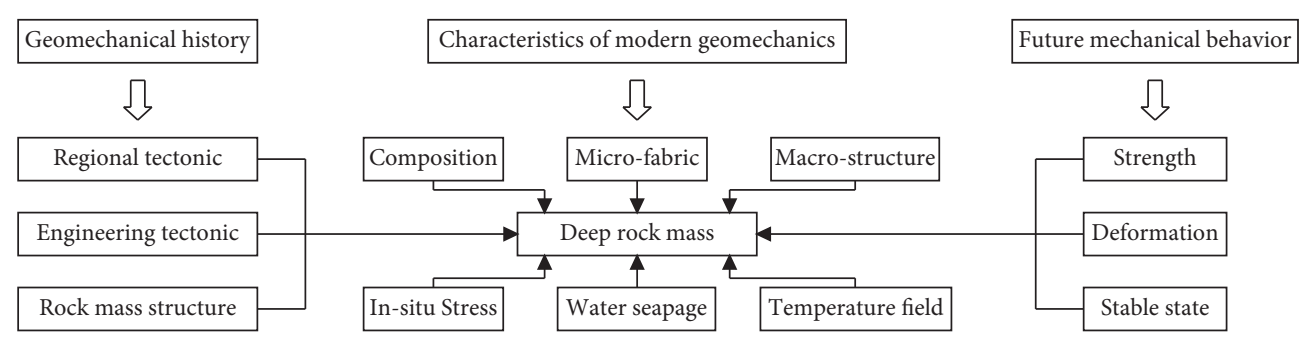

FIgURE 2: Geomechanical characteristics of deep rock mass [4].

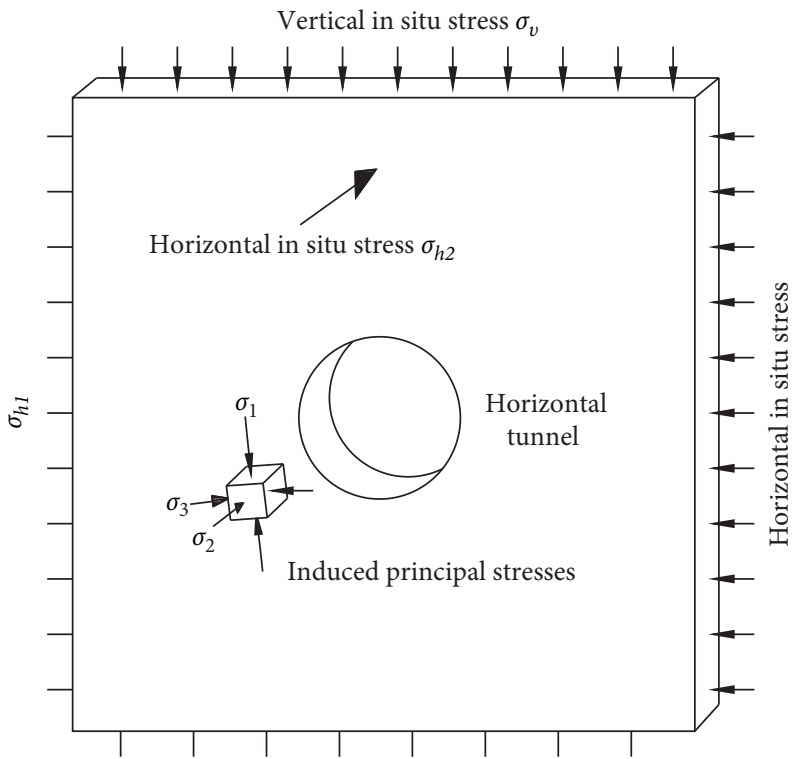

FIGURE 3: Stresses induced in the rock surrounding a horizontal tunnel [5].

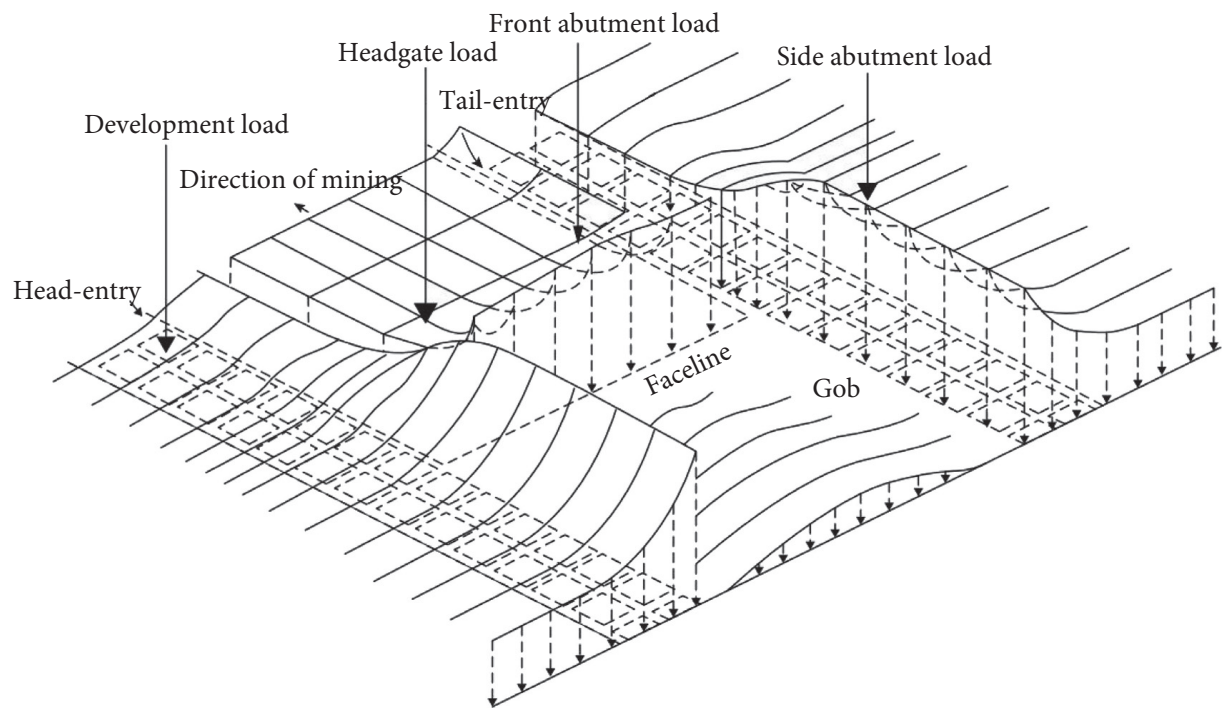

FIgURE 4: Mining-induced stress around a longwall mining panel [6].

[7-11]. Jiang et al. [12] found that with the increase of mining height, the stress reduction area adjacent to a coal face expanded, the peak abutment pressure decreased, the peak influence area moved forward, and the influence area expanded. The greater the bearing capacity of the gob, the lower the load on the solid surrounding rock, and vice versa; the gob will affect the concentration, range, and orientation of the mining-induced stress in the surrounding rock and 
also affect the shape and size of the plastic zone of openings in the coal or rock mass [13]. The mining-induced stress increases with reduced coal seam thickness [14]; the maximum vertical stress decreases with increased working height during depillaring [15]. Geologic discontinuities, especially faults and foliation as well as mining procedures, also control the orientation and magnitude of stresses in surrounding rock [6].

2.2. In Situ Measurement of Mining-Induced Stresses. Research on stresses around mine openings can be divided into three categories: (1) theoretical studies of a purely mathematical or mechanical character, (2) physical simulation tests intended to examine the stress conditions, and (3) observation and measurement [16]. Examples of some of these methods include theoretical analysis [17-25], numerical simulation [26-28], and physical simulation [29-31]. However, this review will focus on in situ measurement of mining-induced stresses.

At present, many measurement methods have been developed to measure the magnitude and orientation of in situ stresses, such as flat jack method, hydraulic fracturing method, acoustic emission method, and stress relief method. On the other hand, monitoring of changes in the in situ stress due to mining mainly includes borehole stress gauge monitoring technology, electromagnetic radiation monitoring technology, and microseismic monitoring technology $[32,33]$. Previously published practices using these methods are shown in Table 1.

The suite of mining-induced stress measurement methods can be divided into direct and indirect methods. The direct measurement methods can directly measure the stress state induced by mining, including hydraulic fracturing method, stress relief method, and stress gauges. The indirect measurement methods measure the changes of certain physical quantities related to stress, such as rock electric resistance, electromagnetic radiation, and elastic wave velocity, and then calculate the mining-induced stress value according to the relationship between these physical quantities and stress. The direct measurement method includes point-location measurements and the monitoring range is limited by the number of stress measurement sensors or instruments. If these methods are used to monitor the range and evolution law of mining-induced stress at a large scale, then a large number of stress measurement sensors need to be installed, and an interpolation method is used to infer the continuous large-scale distribution of mining-induced stress, all of which can be very expensive and time-consuming to implement. The indirect measurement method shows a good prospect of the analysis of mining-induced stress at a larger scale than point-measurements and throughout the entire volume of a rock mass.

\section{Rock Mechanics for Mining Engineering}

Mining-induced stress is the fundamental cause of deformation and instability for all underground mines and openpit mines. Without the disturbance from mining excavations, the rock mass is in its initial equilibrium state. The mining activities change the original equilibrium state of the rock mass, causing deformation and movement of the rock mass towards the excavation, resulting in the redistribution of stress around mine openings [46]. The deformation and subsequent mining-induced stress concentration within the surrounding rock can result in local or overall instability and failure of the surrounding rock (Figures 5(a) and 5(b)), including the possibility of rock bursts (Figure 5(c)).

Martin et al. [47] analyzed the potential stress paths that exist within a rock mass around underground mine openings. In addition to the variation of magnitude of three principal stresses, the orientation of these stresses is also rotating at the same time [48]. The paths of mining-induced stress varied according to the mining activities (Figure 6), which can instruct the laboratory rock mechanics tests. According to the distribution of the abutment pressure of the coal and rock mass in front of the working face under different mining methods, Xie et al. [1] proposed stress paths under the conditions of protected coal seam mining, topcoal caving mining, and nonpillar mining for rock mechanics tests (Figure 7). According to the experimental results of rock mechanics tests under mining-induced stress paths, we can have a deeper understanding of the deformation and failure characteristics of surrounding rock. The failure modes of the surrounding rock can be divided into relaxation and stress-driven failures. The most commonly recognized modes are related to shear failure, which occurs along block boundaries or through the rock mass (Figure 8).

\section{Microseismic Monitoring and Seismic Velocity Tomography}

4.1. Microseismic Monitoring. Mining-induced stress concentration results in rock fracturing, fracture sliding, or even fault-slip events. During these processes, seismic events with different intensity will be generated. At present, routine microseismic monitoring has become one of the most effective methods to help us understand the mining-induced rock failure mechanism and hence the surrounding rock stability. Microseismic monitoring also provides an effective tool for rating seismic hazards and providing alerts to potential rock mass instabilities in underground mines [50-56]. Jiang et al. [57] introduced the microseismic monitoring system developed by CSIRO for monitoring of induced fractures in coal mines. Li et al. [58] installed the first 16-channel full digital microseismic monitoring system in Fankou Lead-Zinc Mine of China, which is used to monitor the rock mass failure and evaluate rock burst hazards. Yang et al. [59] studied the time and space distribution of seismic events in the first mining area of Dongguashan Copper Mine, put forward a method to identify the risk of underground engineering rock mass, and established the working procedure of mining analysis in high stress areas based on microseismic monitoring technology which was verified by the actual events. Xia et al. [60] analyzed the distribution characteristics of microseismic events in front of a working face. Based on the engineering example 
TABLE 1: Frequently used mining-induced stress measurement methods.

\begin{tabular}{|c|c|c|c|c|c|c|}
\hline Mine & Mining method & Ore type & $\begin{array}{l}\text { Mining depth } \\
(\mathrm{m})\end{array}$ & Method & $\begin{array}{l}\text { Measuring } \\
\text { range }\end{array}$ & Reference \\
\hline- & Longwall mining & Coal & 230 & Hydraulic fracturing & Point & {$[34]$} \\
\hline Lockerby Mine & Open stope & Nickel & $1050-1110$ & Seismic tomography & $\begin{array}{l}\text { 34-36 sill } \\
\text { pillar }\end{array}$ & {$[35]$} \\
\hline- & Longwall mining & Coal & 335.28 & Seismic tomography & Coal pillar & {$[36]$} \\
\hline $\begin{array}{l}\text { Willow Creek } \\
\text { Mine }\end{array}$ & Longwall mining & Coal & 213.36 & Biaxial stressmeter & Point & {$[37,38]$} \\
\hline Zhangji Coal Mine & Longwall mining & Coal & $617.2-664.2$ & Electromagnetic radiation & Panel & {$[39]$} \\
\hline $\begin{array}{l}\text { Nuodong Coal } \\
\text { Mine }\end{array}$ & Longwall mining & Coal & $228-480$ & Electromagnetic radiation & Panel & {$[40]$} \\
\hline Beiming Iron Mine & $\begin{array}{l}\text { Sublevel caving without sill } \\
\text { pillar }\end{array}$ & Iron & $265.76-679$ & Stress relief & Point & {$[41]$} \\
\hline $\begin{array}{l}\text { Liangbei Coal } \\
\text { Mine }\end{array}$ & Longwall mining & Coal & $455.38-477.38$ & Borehole stress gauge & Point & {$[42]$} \\
\hline $\begin{array}{l}\text { Tangkou Coal } \\
\text { Mine }\end{array}$ & Longwall mining & Coal & 1100 & Borehole stress gauge & Point & {$[43]$} \\
\hline $\begin{array}{l}\text { Lazy Collieries and } \\
\text { CSM Mine }\end{array}$ & Longwall mining & Coal & $690-980$ & $\begin{array}{c}\text { Compact } \\
\text { conical-ended borehole } \\
\text { monitoring }\end{array}$ & Point & {$[44]$} \\
\hline Dariba Mine & $\begin{array}{l}\text { Vertical retreat mining } \\
\text { and blast hole stoping }\end{array}$ & Lead-zinc & $500-600$ & $\begin{array}{l}\text { Hydraulic tests on } \\
\text { preexisting fracture }\end{array}$ & Point & {$[27]$} \\
\hline $\begin{array}{l}\text { Laohutai Coal } \\
\text { Mine }\end{array}$ & Longwall mining & Coal & $410-911$ & Focal mechanism & Mine & {$[45]$} \\
\hline
\end{tabular}

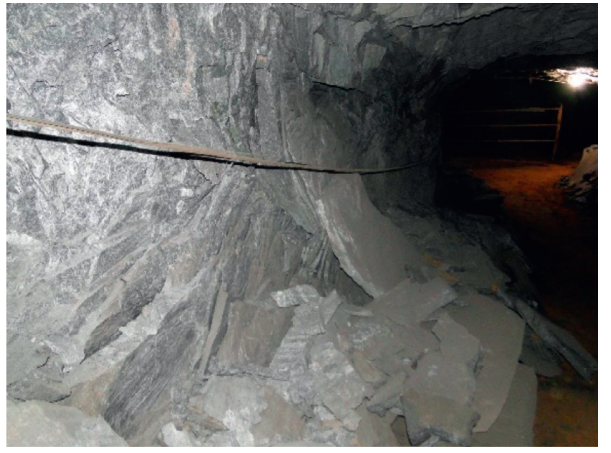

(a)

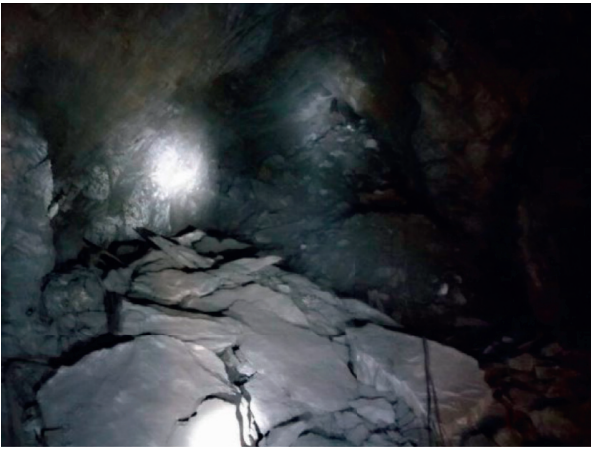

(b)

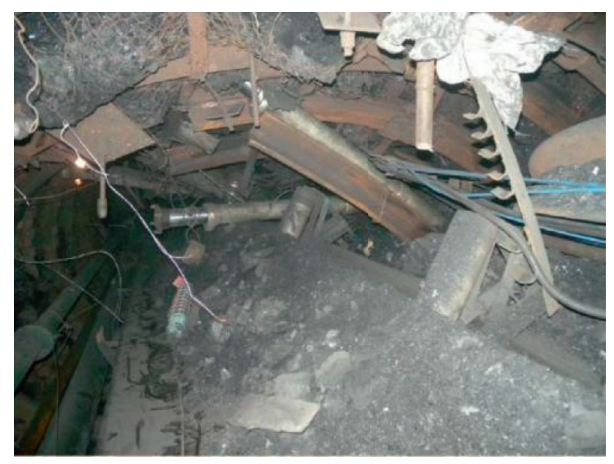

(c)

FIgURE 5: Spalling (a), roof fall (b), and rock burst (c) caused by mining-induced stress concentration.

of Shirengou Iron Mine, Zhang et al. [61] analyzed the generation, accumulation, and evolution law of microfractures in the surrounding rock during the formation of an underground goaf and open-pit drainage in the area near No. 15 exploration line of the mine. Wang et al. [62] designed the double-roadway panel layout to install stress gauges and microseismic monitoring systems in the outer roadway and obtained the abutment pressure evolution process and seismicity characteristics around the goaf. Based on the KJ 768 coal mine microseismic monitoring system, Ouyang et al. [63] carried out the prediction of the dynamic load of the shallow coal seam using self-powered 


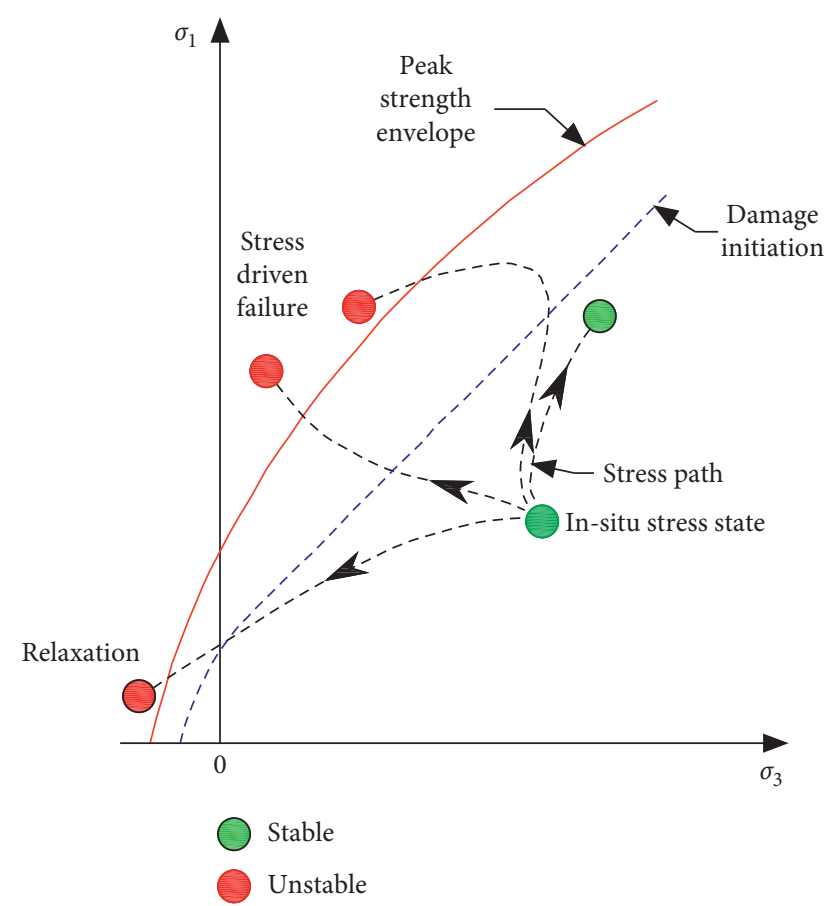

FIGURE 6: Illustration of possible stress paths near underground openings.

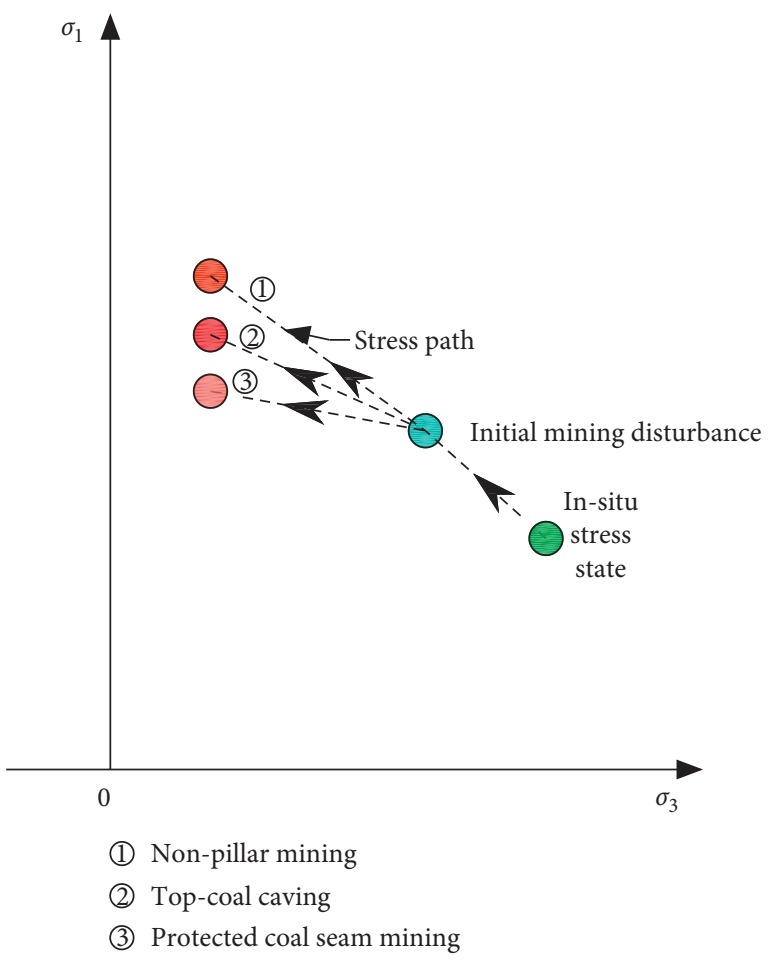

FIGURE 7: Stress paths for laboratory rock mechanics tests with different coal mining methods.

microseismic monitoring system. Based on the results of FLAC3D stress analysis, Liu et al. [64] installed a 19-channel microseismic system to monitor the stability of surrounding rock of the hanging wall. Surface arrays can also be used in mining-induced seismicity monitoring. Swanson et al. [65] installed an array with ten triaxial strong-motion sensors on the surface above two underground longwall coal mines in western Colorado (USA); this array covers about 250 square kilometers and can automatically process data. Boltz et al. [66] deployed two temporary arrays above two underground longwall panels and were successful in detecting mining-induced events. Compared with the traditional mine microseismic monitoring system, the surface monitoring array has the advantages of convenient installation, flexible layout, versatility, no terrain restrictions, and low cost. However, the monitoring period is limited by the battery capacity of the sensors, but high-efficiency solar power generation and high-capacity battery technology can effectively overcome this problem.

To carry out a successful and high-quality microseismic monitoring program, the system should be designed correctly. Ge [67] proposed five principles for the design of mine microseismic monitoring system: (1) the monitoring rock mass should be in three-dimensional space; (2) the sensors should not only be arranged in the target area but also be installed in the surrounding rock mass; (3) the sensor layout should be balanced; (4) the appearance of a twodimensional array should be avoided because the accuracy in the direction perpendicular to the plane is low; (5) special sensor pairs should be designed to improve the coverage at specify locations. A typical microseismic system is made up of a number of unique components including sensors, junction box, ethernet communication, acquisition PC, and processing PC (Figure 9).

4.2. The Relationship between Wave Velocity and Stress. There are three basic types of seismic waves: surface waves, P-waves, and S-waves (Figure 10). Rayleigh and Love waves are called surface waves, which propagate along the Earth's surface [70]. The P-wave, also known as the longitudinal wave or first arrival wave, propagates through the rock mass causing expansion and compression of the rock. The P-wave is the fastest wave and, hence, is the first wave to arrive at a sensor. S-waves, also called shear waves, propagate in the medium causing the particles in the medium to move perpendicular to the direction of wave propagation direction. The calculation formulae for P-wave and S-wave velocity are as follows:

$$
\begin{aligned}
& V_{P}=\sqrt{\frac{(1-v) E}{(1+v)(1-2 v) \rho}}, \\
& V_{S}=\sqrt{\frac{E}{2(1+v) \rho}},
\end{aligned}
$$

where $E$ is the elastic modulus of medium $(\mathrm{Pa}), v$ is the Poisson's ratio of medium, and $\rho$ is the density of medium $\left(\mathrm{kg} / \mathrm{m}^{3}\right)$.

Rock types, texture, density, porosity, anisotropy, stresses, and water content have an impact on the propagation of elastic waves in intact rocks [71]. With the increase of confining stresses, the cracks and pores in the rocks tend to close, which will lead to the increase of Young's modulus and thereby affect the velocity of both P-and S-waves. In the field of seismic tomography in underground mines, the wave 


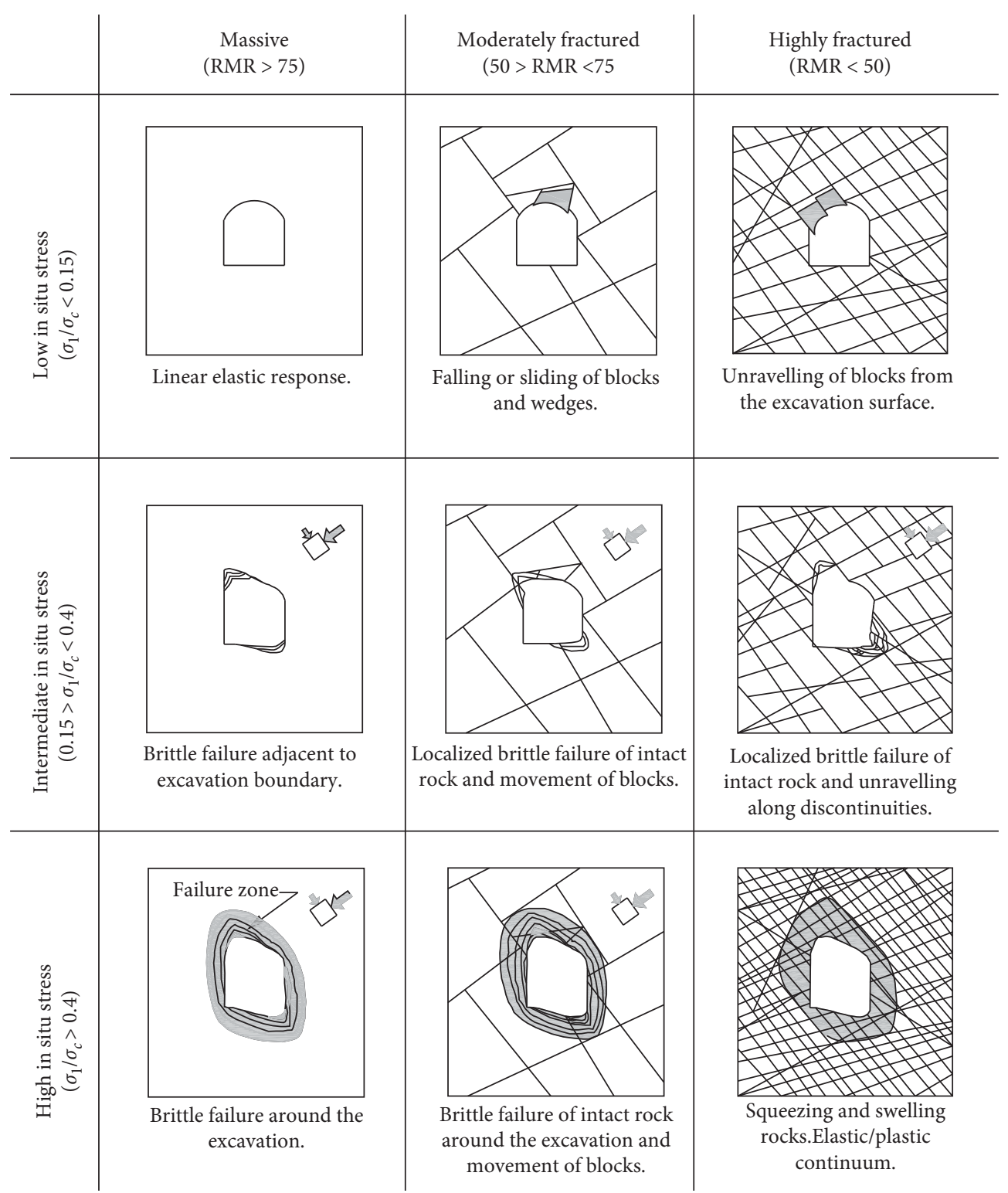

Figure 8: Failure modes for underground openings [49].

velocity variation has often been used as an indicator of stress level changes [72, 73].

To accurately estimate the stress level, the relationship between stress and velocity has been studied by many researchers. In the early research, the studies mainly focused on the change of seismic wave velocity in the deep earth with the stress field at different depths, especially the relation between P-wave velocity and stress [74]. After the 1960s, the studies transformed to laboratory and in situ experiments to examine the relationship between stress and wave velocity. When the stresses increase, the wave velocities will increase in varying magnitudes, which depends on the angle between the stress loading direction and the wave velocity propagation direction [75]. Engelder and Plumb [76] found that the P-wave velocity in granite and sandstone is related with the loading direction of maximum compression stress. Sayers and Kachanov [77] used second-order and fourth- order crack density tensors to characterize rock anisotropy and found that the wave velocity parallel to and perpendicular to the maximum compression stress is a function of the difference of the maximum compressive stress and confining pressure. Huang et al. [78] compared acoustoelastic theory with the microcrack model, the error between these two models was within $2 \%$, and the theory of acoustoelasticity can be seen as a macroscopic description of the microcrack model. Many empirical formulae were also proposed (Table 2).

4.3. Theory Basis of Seismic Velocity Tomography. The method for tomography was developed by [85]. By stimulating physical signal outside the object and receiving the signal which is carrying the internal information passing through the object, the distribution of physical parameters inside the object is 


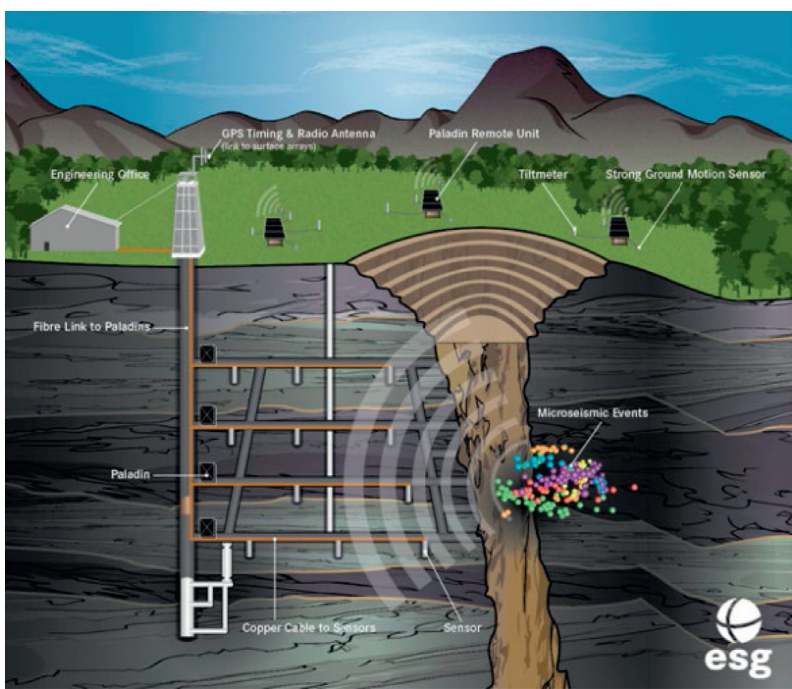

FIgURE 9: Typical microseismic monitoring system [68].

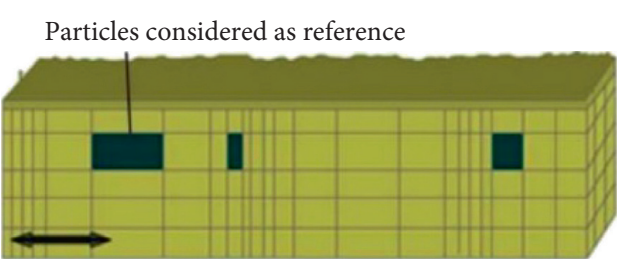

$\mathrm{P}$ waves

(a)

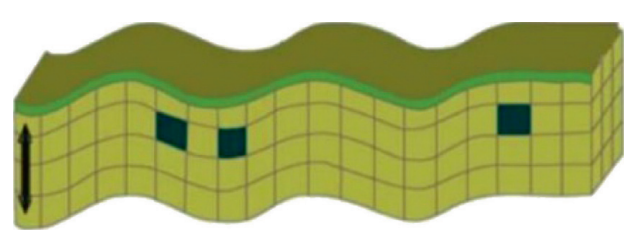

S waves

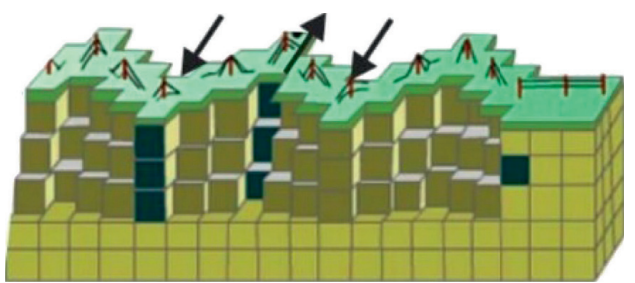

Love waves

(b)

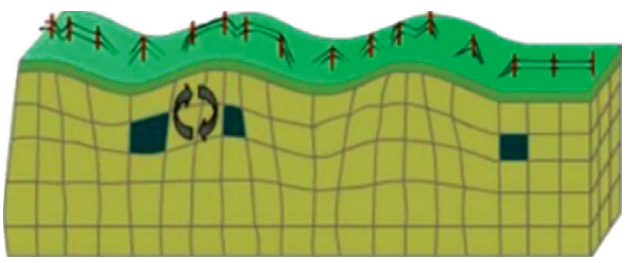

Rayleigh waves

Direction of wave propagation

(c)

(d)

Figure 10: Types of seismic waves (modified from [69]).

TABLE 2: Relation between stresses and elastic wave velocity.

\begin{tabular}{|c|c|c|c|}
\hline Formulae & \multicolumn{2}{|c|}{ Parameters } & References \\
\hline$V(P)=A(P / 100)^{a}+B\left(1-e^{-b P}\right)$ & $A, a, B$, and $b$ are fitting coefficients & & [79] \\
\hline$V^{2}=A_{1}+B_{1} P+C_{1} e^{\left(-\left(P / \tau_{1}\right)\right)}$ & $A, B C$ and $\tau$ are fitting coefficients & $P$ is the confining pressure for dry & [80] \\
\hline$V=A_{2}+B_{2} P+C_{2} e^{\left(-P / \tau_{2}\right)}$ & $A, B, C$, and $\tau$ are nttıng coefticients & $\begin{array}{l}\text { samples (entective stress for saturated } \\
\text { samples), } \mathrm{V} \text { is the } \mathrm{P} \text { - or }\end{array}$ & \\
\hline$V=A+K P-B e^{-D P}$ & $A, K, B$, and $D$ are fitting coefficients & $\begin{array}{l}\text { samples), } \text { is the } P \text { - or } \\
\text { S-wave velocity }\end{array}$ & [81] \\
\hline$V=A-B e^{-D P}$ & $\begin{array}{c}A, B \text {, and } D \text { are fitting coefficients } \\
V_{P} \text { is the } P \text {-wave velocity, } T_{33} \text { is the }\end{array}$ & & {$[82]$} \\
\hline$V_{P}=\phi\left(T_{33}\right)^{\psi}$ & $\begin{array}{c}\text { compression stress, } \phi \text { and } \psi \text { are fitting } \\
\text { coefficients }\end{array}$ & - & {$[83]$} \\
\hline$V=a \sigma+b$ & $a$ and $b$ are fitting coefficients & $\mathrm{V}$ is the $\mathrm{P}$ - or $\mathrm{S}$-wave velocity & {$[84]$} \\
\hline
\end{tabular}


inversed according to certain physical and mathematical relations, and the two-dimensional or three-dimensional image inside the object is reconstructed by using computer image reconstruction technology. This theory also applies to threedimensional problems and corresponds to many physical experiments in fields such as medicine and geophysical imaging. Deans [86] reviewed the transformation and its applications, and the transformation was named after Radon. For velocity tomography in deep mines, the probe is the mininginduced seismic waves, the velocity distribution in the rock mass is the unknown function, and the velocity profile function can be determined by probing the rock mass with the mininginduced seismic waves [87].

Velocity tomography relies on the relationship between time, distance, and velocity of a ray traveling through rock mass, where the rock mass is divided into discrete units termed "voxels." According to this relationship, the travel times between events and sensors can be calculated as follows:

$$
\begin{aligned}
v & =\frac{l}{t} \longrightarrow v t=l, \\
t & =\int_{S}^{R} \frac{1}{v} \mathrm{~d} l=\int_{S}^{R} p \mathrm{~d} l, \\
t_{i} & =\sum_{j=1}^{M} p_{j} l_{i j}, \quad(i=1, \ldots, N), \\
p & =\frac{1}{v},
\end{aligned}
$$

where $v$ is the wave velocity $(\mathrm{m} / \mathrm{s}), l$ is the distance between events and sensors $(\mathrm{m}), t$ is the travel time $(\mathrm{s}), p$ is the slowness $(\mathrm{s} / \mathrm{m}), N$ is the number of rays, and $M$ is the number of voxels [88]. If the travel time, travel distance, and voxel's slowness are assigned to corresponding matrices, the velocity can be determined by using the following equation [89]:

$$
\mathbf{T}=\mathbf{D P} \longrightarrow \mathbf{P}=\mathbf{D}^{-1} \mathbf{T},
$$

where $\mathbf{T}$ is the travel time matrix $(1 \times \mathrm{N})$, $\mathbf{D}$ is the travel distance matrix $(N \times M)$, and $\mathbf{P}$ is the slowness matrix $(1 \times M)$. As the inverse problems are either underdetermined (more voxels than rays) or overdetermined (more rays than voxels), so the most effective way to solve the inverse problem is using the iteration methods. The iteration process will stop when the residual time is less than the preset value. The algorithms developed to solve the inverse equation include least squares, damped least squares, and singular value decomposition (SVD) [87].

Double-difference tomography was developed by $[90,91]$, which jointly inverts the three-dimensional wave velocity structures and the relative and absolute position of seismic source. The input data include both absolute and differential travel times. The absolute travel time data are mainly used to determine the velocity structure outside the source area, and the differential time data are primarily used to determine the fine structure of the source area. Waveform cross-correlation was used to calculate the differential travel times. Results have shown that the double-difference tomography can generate high-quality tomograms of the seismic zone structure $[90,91]$. The standard double-difference tomography method can be described by equations (5) and (6). Equation (5) is used for absolute data, while equation (6) is used for differential data.

$$
\begin{aligned}
T_{k}^{i}= & \tau^{i}+\int_{i}^{k} \delta u \mathrm{~d} s, \\
r_{k}^{i}= & \sum_{m=1}^{3} \frac{\partial T_{k}^{i}}{\partial x_{m}^{i}} \Delta x_{m}^{i}+\Delta \tau^{i}+\int_{i}^{k} \delta u \mathrm{~d} s, \\
r_{k}^{i}-r_{k}^{j}= & \sum_{l=1}^{3} \frac{\partial T_{k}^{i}}{\partial x_{l}^{i}} \Delta x_{l}^{i}+\Delta \tau^{i}+\int_{i}^{k} \delta u \mathrm{~d} s \\
& -\left(\sum_{l=1}^{3} \frac{\partial T_{k}^{j}}{\partial x_{l}^{j}} \Delta x_{l}^{j}+\Delta \tau^{j}+\int_{i}^{k} \delta u \mathrm{~d} s\right),
\end{aligned}
$$

where $T_{k}^{i}$ is the observed arrival time from event $i$ to sensor $k, \tau^{i}$ is the occurrence time of event $i, r_{k}^{i}$ is the difference between theoretical arrival time and observed arrival time (event $i$ to sensor $k$ ), ds is the element of path integral, $\tau^{i}$ is the event time perturbation (event $i), x_{1}^{i}, x_{2}^{i}, x_{3}^{i}$ are the event location perturbations (event $i$ ), and $\delta \mathbf{u}$ is the slowness perturbation.

The general procedure for tomography follows a similar approach regardless of the precise inversion method used. The travel times between events and sensors are plotted to indicate the quality of the input data, the appropriate extents of the voxels and voxel size are selected based on the number and distribution of rays which are available, and then an initial velocity is corrected based on the measured travel times on an iterative basis. The velocity model is iteratively corrected until the difference between the measured travel times and the calculated travel times reaches an acceptable level. Westman et al. [92] provided an example of the typical calculation approach.

For time-lapse tomography, the traditional approach contains three steps: (1) divide the data into different time intervals; (2) conduct seismic tomography in each time interval; (3) calculate the temporal velocity changes by subtracting velocity models for two adjacent time intervals. Qian et al. [93] proposed an advanced time-lapse tomography scheme by using double-difference tomography method. In this new scheme, event $i$ and event $j$ are seismic events in two different time intervals. Supposing that event $i$ happens in time interval 1 and event $j$ happens in time interval 2, equation (6) will be transformed into equation (7). This method overcomes the difference of seismic ray distribution in different time periods to a certain degree.

$$
\begin{aligned}
r_{k}^{i}-r_{k}^{j}= & \sum_{l=1}^{3} \frac{\partial T_{k}^{i}}{\partial x_{l}^{i}} \Delta x_{l}^{i}+\Delta \tau^{i}+\int_{i}^{k} \delta u_{1} \mathrm{~d} s \\
& -\left(\sum_{l=1}^{3} \frac{\partial T_{k}^{j}}{\partial x_{l}^{j}} \Delta x_{l}^{j}+\Delta \tau^{j}+\int_{j}^{k} \delta u_{2} \mathrm{~d} s\right) .
\end{aligned}
$$


4.4. The Applications of Velocity Tomography in Mining Engineering. Velocity tomography has been used for imaging the rock mass conditions or stress state with seismic waves produced by mining-induced microseismic events or explosions, and it is solved as an inverse problem [94]. There are many factors which affect the quality of velocity tomography results, such as high-resolution source location methods, accurate arrival time picking, efficient inversion algorithms, and ray tracing methods. In the field of mining engineering, tomographic imaging is mainly used in exploration and ore body delineation, geological structure and discontinuity detection, rock mass stability monitoring, and rock burst hazard prevention.

According to the source types, velocity tomography can be divided into controlled source and passive velocity tomography $[95,96]$. Controlled source velocity tomography is the technology that inverts arrival times into a velocity distribution field using seismic energy from artificial sources (blasting (Figure 11) or hammering). The advantage of this method is that the location of the sources is known, and the arrangement of the sources and sensors can be optimized manually to achieve the optimal ray coverage, and hence images, of velocity tomography [83]; its disadvantage is that it is more difficult to realize long-term continuous monitoring. Passive velocity tomography is the technology that uses microseismic events or natural earthquakes as the sources for inverting the velocity field. Microseismic events with different magnitudes will be generated in the process of mining-induced rock mass fracturing, and the elastic wave will be excited in the surrounding rock (Figure 12). The advantages of this technology are as follows: (1) wide monitoring range, that is, velocity tomography at mine scale or regional scale can be realized by reasonably designing the location and quantity of sensors; (2) it has the ability to carry out long-term continuous passive velocity tomography analysis in the study area. However, it also has disadvantages: (1) due to the limitation of time picking and source location algorithms, the calculated event location may deviate from its actual position; (2) the mined-out area formed by mining activities leads to less ray coverage in many areas, resulting in low reliability of the tomography results in those areas with limited ray coverage.

Velocity tomography has been shown to be an efficient method to analyze the mining-induced stress distribution in both coal and hard rock underground mines $[35,36,99$, 100]. High mining-induced stress will result in the closing of fractures, cracks, voids, and pores, thereby increasing the elastic wave velocity. When the mining-induced stress continues to increase, the elastic wave velocity will be reduced due to the formation of new cracks. Through comparing the velocity field with mining activities, we can better understand the mining-induced stress distribution and evolution characteristics. When the mining-induced stress distribution was imagined with $\mathrm{P}$-wave, SV-wave, and $\mathrm{SH}$-wave travel time tomography, the SV tomograms can clearly reflect the vertical stresses within panels and has a good correlation with the predicted stress by theory [101]. Luxbacher et al. [88] studied the velocity distribution characteristics of a longwall panel using time-lapse tomography technology. They found that the high-velocity zones are located at places where high abutment stress is expected, and the result compared well to the numerical modeling simulation results (using the LAMODEL modeling software). Figure 13 shows an example of mininginduced stress and the velocity distribution in a longwall panel and the LAMODEL plots for Day 18 of the study and the tomogram also in the same day. Seismic tomography has also been used in underground hard rock mining, and the mining-induced stress evolution has been estimated by using passive seismic tomography [102-104]. Usually, the low-velocity zones may indicate excavations or surrounding rock fracturing caused by mining-induced stress, whereas the high-velocity zones are likely caused by mining-induced stress concentration or anomalous geology structures. By using seismic tomography, Ma et al. [105] found that high-velocity zones variation agree well with seismicity rates (Figure 14), which indicates that seismicity rates are positively correlated with the mininginduced stress concentration.

Seismic tomography is a promising way for mininginduced hazard evaluation and prediction [106-109]. Dubinski and Dworak [110] proposed a seismic criterion for detecting of seismic hazard zones by using the extent and position of the mining-induced velocity anomaly zones, the velocity anomaly $(A)$, and the background velocity $\left(V_{0}\right)$ :

$$
A=\frac{V_{\max }-V_{0}}{V_{0}} .
$$

The magnitude of stress increase can be estimated from parameters given in Table 3. The table was given based on laboratory and in situ measurement at Upper Silesian Coal Field, and only applicable to the mining and geological conditions of this coal field. When the velocity anomaly zones are located near mining excavations, it will have large influence on the occurrence of rock burst accident. In the study of [111], they found that the zone of high velocity, high seismic anomaly, and high gradient velocity has been observed very clearly near 2Jd gateroad, and the passive tomographic velocity images turned out to be very useful as long-term precursors of seismic-prone areas. Gong [83] proposed an assessment model of seismic hazard in his model consisting of two equations: 

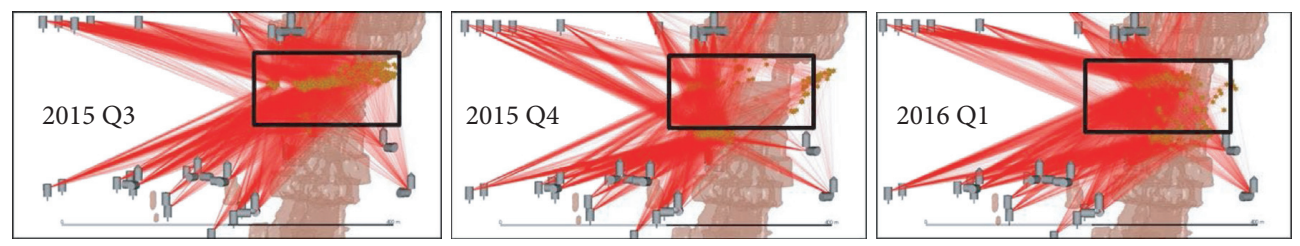

FIGURE 11: Ray path geometries of controlled source velocity tomography (blasts ( $)$ )[97].

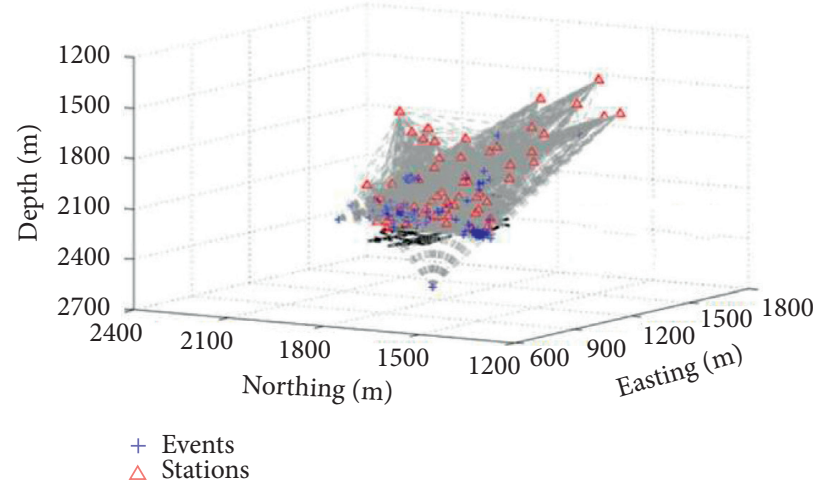

FIGURE 12: Ray path coverage of passive source velocity tomography [98].

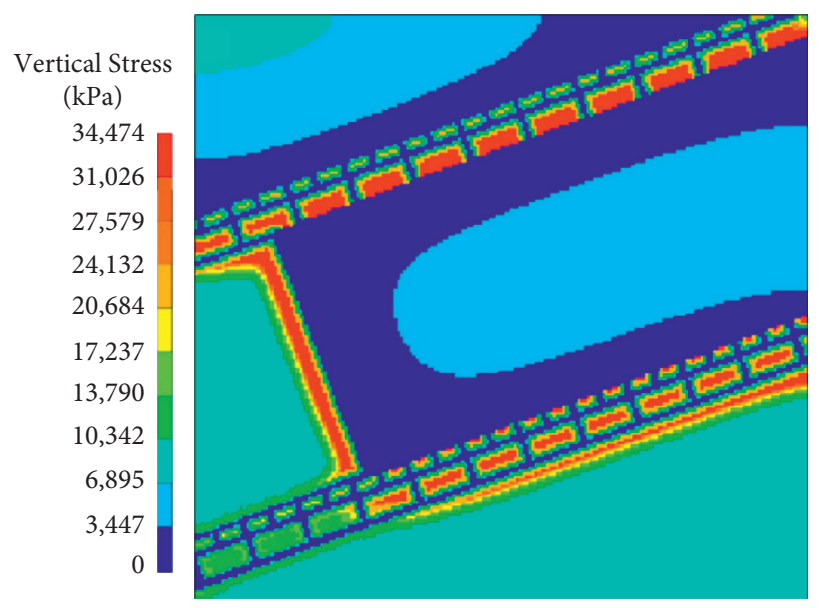

(a)

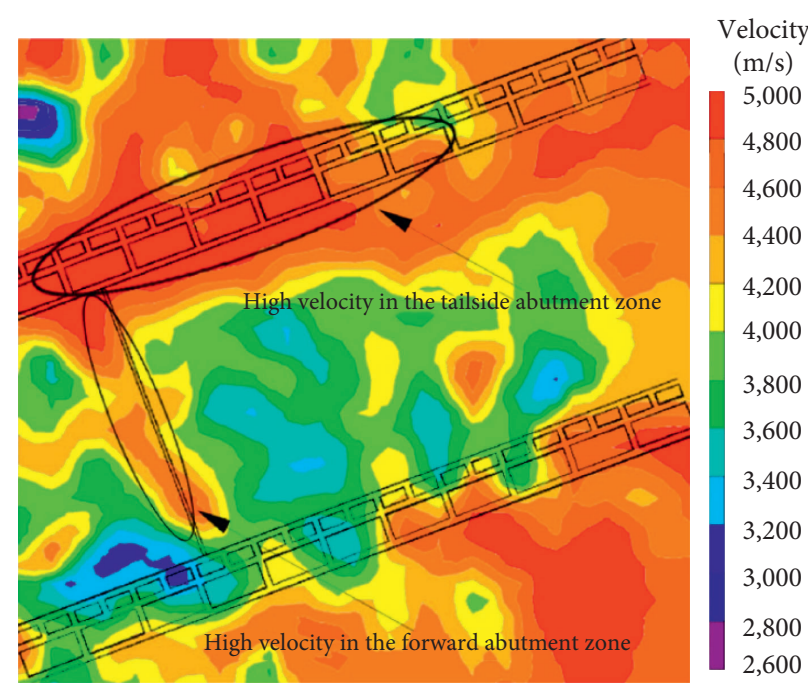

(b)

FIGURE 13: LAMODEL vertical stress (a) and velocity tomogram (b) [88].

$$
\begin{aligned}
& A_{n}=\frac{V_{p}-V_{p}^{a}}{V_{p}^{a}}, \\
& A_{n}=\frac{\mathrm{VG}^{-} \mathrm{VG}^{a}}{\mathrm{VG}^{a}},
\end{aligned}
$$

$$
\operatorname{VG}(i, j)=V(i, j) \operatorname{Grad}(i, j), \quad \text { for point }(i, j)
$$




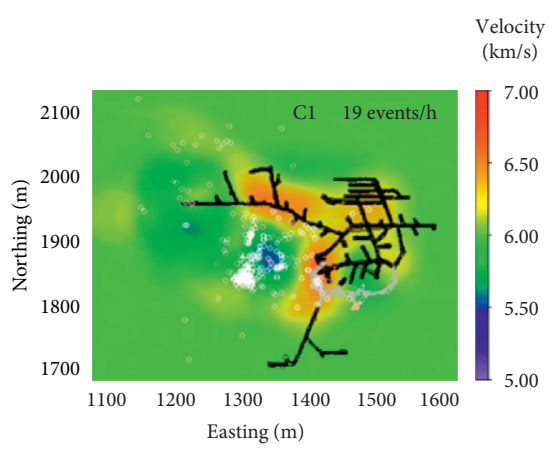

(a)

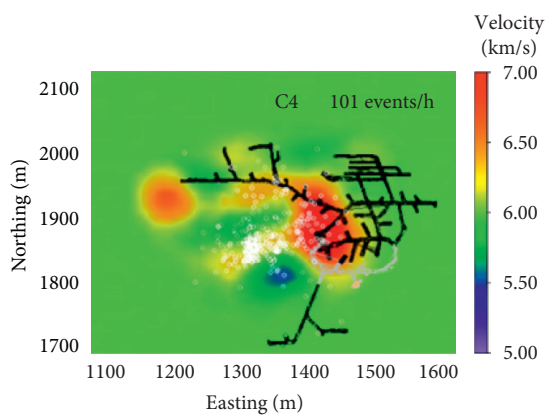

(d)

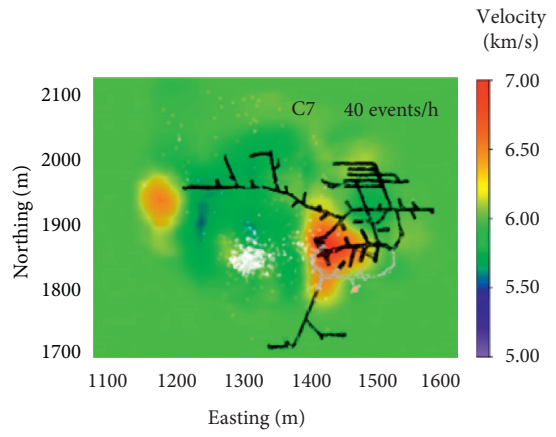

(g)

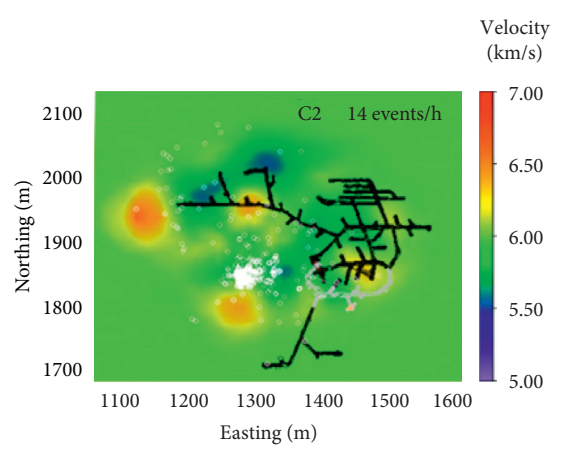

(b)

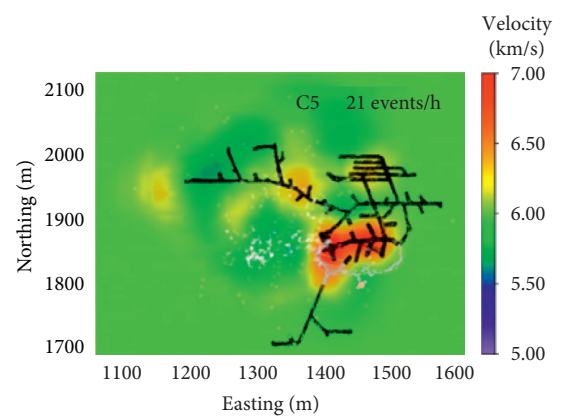

(e)

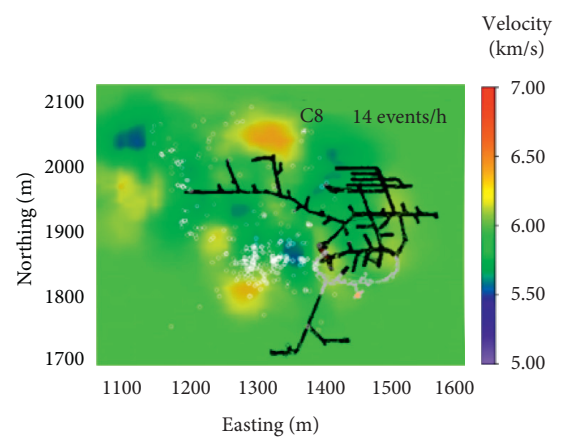

(h)

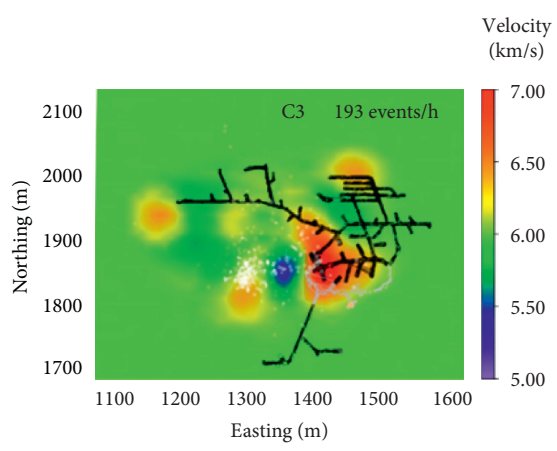

(c)

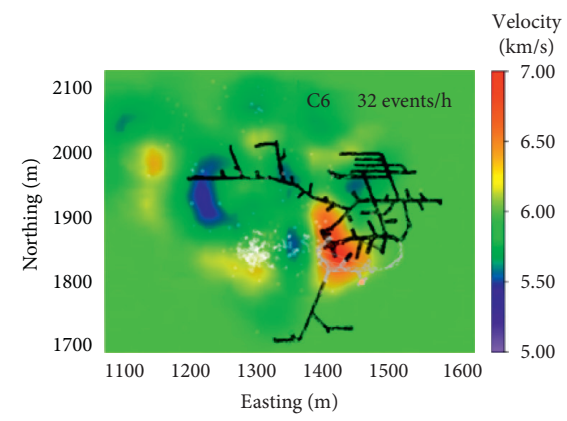

(f)

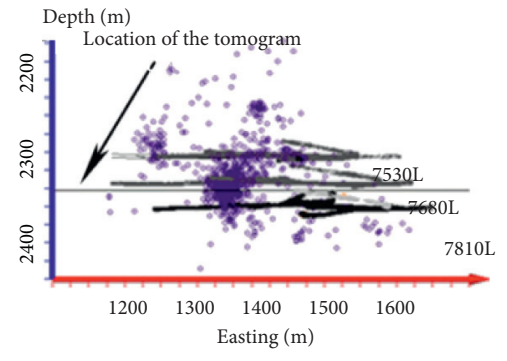

(i)

Figure 14: Tomograms of Period C1 to Period C8 at Creighton Mine [105].

TABle 3: The degree of mining-induced stress evaluation [11].

\begin{tabular}{lccc}
\hline Degree of stress & Characteristics of stress increase & Velocity anomaly for P-wave in coal, A (\%) & Probable stress increase, $p / p_{0}(\%)$ \\
\hline 1 & None & $<5$ & $<10$ \\
2 & Low & $5-15$ & $10-50$ \\
3 & Medium & $15-25$ & $50-100$ \\
4 & High & $>25$ & $>100$ \\
\hline
\end{tabular}

$$
\operatorname{Grad}(i, j)=\max \left(\begin{array}{c}
\frac{V(i, j)-V(i-1, j-1)}{\sqrt{2} d}, \frac{V(i, j)-V(i-1, j+1)}{\sqrt{2} d}, \frac{V(i, j)-V(i+1, j+1)}{\sqrt{2} d}, \\
\frac{V(i, j)-V(i+1, j-1)}{\sqrt{2} d}, \frac{V(i, j)-V(i-1, j)}{d}, \frac{V(i, j)-V(i+1, j)}{d}, \frac{V(i, j)-V(i, j-1)}{d}, 0
\end{array}\right),
$$


TABLE 4: The seismic risk index and mining-induced stress concentration degree based on the positive velocity anomaly [83].

\begin{tabular}{lcc}
\hline Seismic risk index & Degree of stress concentration & Velocity anomaly (positive), An (\%) \\
\hline 0 & None & $<5$ \\
1 & Weak & $5-15$ \\
2 & Middle & $15-25$ \\
3 & Strong & $>25$ \\
\hline
\end{tabular}

TABLE 5: The seismic risk index and mining-induced stress difference degree based on VG anomaly [83].

\begin{tabular}{lcc}
\hline Seismic risk index & Degree of stress difference & VG anomaly, An (\%) \\
\hline 0 & None & $<5$ \\
1 & Weak & $5-15$ \\
2 & Middle & $15-25$ \\
3 & Strong & $>25$ \\
\hline
\end{tabular}

where $V_{p}$ is the $\mathrm{P}$-wave velocity, $V_{p}^{a}$ is the average $\mathrm{P}$-wave velocity, VG is the variation degree of velocity gradient, which can be calculated by equation $(11), \operatorname{Grad}(i, j)$ is the $\mathrm{P}$-wave velocity gradient, $V(i, j)$ is the $\mathrm{P}$-wave velocity, and $\mathrm{VG}^{a}$ is the average VG. Table 4 shows the relation between positive anomaly of P-wave velocity and seismic risk, and Table 5 shows the relation between VG anomaly and seismic risk. Gong et al. [112] also developed an adaptive-grid passive seismic tomography method to identify rock burst risk. Li et al. [113] proposed spatio-temporal assessment method to evaluate rock burst hazard potential for underground coal mining, which combines b-value and seismic tomography (Figure 15). Afrouz et al. [114] developed an innovative concept of hazardous thresholds, which was integrated from the catalog of underground mine blast rate, energy index, b-value, and P-wave velocity. The velocity increased in the nearby rock mass of high magnitude microseismic events before they were triggered, and then stress decreased in the relaxation process after the high magnitude microseismic events [98].

Rock mass quality and depth of fractured zones are important parameters for the evaluation of the stability of roadways, stopes, shafts, etc. As there is a close relationship between seismic parameters and mechanical properties, the seismic tomography is useful for fracture-mapping and also for evaluation of rock mass quality $[115,116]$. Meglis et al. [117] conducted ultrasonic velocity tomography of a mineby tunnel. When compared with induced stress distribution characteristics, they found that wave velocities and amplitudes in the tensile stress region are lower than that in the compressive stress region; the tensile stress region shows significant anisotropy, which indicates the rock cracking phenomenon in the tensile stress region. The inferred fractured zone depth is $1 \mathrm{~m}$, which is consistent with the microseismic activity before and after excavation. Westman et al. [92] conducted time-lapse tomography using doubledifference tomography for an underground hard rock mine; the aim is to monitor the spatial evolution of a block cave; the data were retrieved from microseismic monitoring system from September through March 2010; the tomography results clearly show the high stress zone during the caving process and the caved height can be inferred combined with the distribution of microseismic events. Melnikov et al. [118] imaged the shallow surface of the Zhelezny open-pit mine and then estimated Poisson's ratio and Young's modulus by using $V_{P} / V_{S}$ values. Poisson's ratios can be used to detect induced fractures or weathering processes in the stepped walls.

Tomographic imaging also can be used in mineral and geology structure exploration in mines. Authors of $[119,120]$ applied seismic tomography to detect the geologic structures in the 1310 longwall panel of Xinji No. 1 coal mine; the results showed that the blind faults have evident linearity, which was validated by the practice; the tomography images also clearly show the coal seam variation and mining-induced fractured zone. Luo et al. [121] designed an experiment to evaluate the application of seismic tomography in the delineation of ore boundaries and characterization of the rock mass; they found that the variations of the mapped velocities along the sides generally coincided with the variations of lithologies already known; the "fast" pyrite mineralization was discriminated from "slow" host lithology from the tomograms (Figure 16). Malehmir et al. [122] depicted a major discontinuity (R8) and a weak zone in the tomograms combined with reflection seismic results and also observed the qualitative corresponding relationship between the P-wave velocity and RQD (Figure 17).

Although velocity tomography has been successfully applied in many practices of mining engineering, there are still deficiencies:

(1) Rock type, tectonic distribution, in situ stress, and other factors all have effect on the background velocity, so it is necessary to understand the regional background velocity distribution characteristics to obtain high-quality tomography results

(2) The relationship between wave velocity and stress is currently only a qualitative relationship which cannot accurately reflect the absolute stress level by tomography results

(3) Tomography results can approximately indicate the stress distribution and evolution characteristics, but it is more difficult to determine the distribution and 


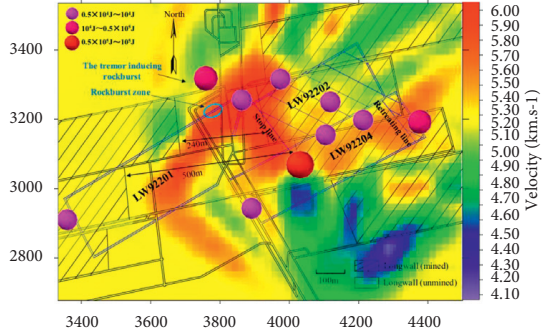

(a)

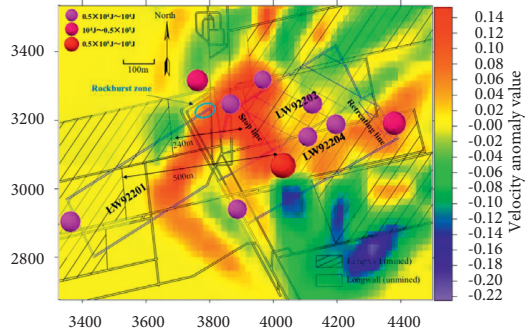

(b)

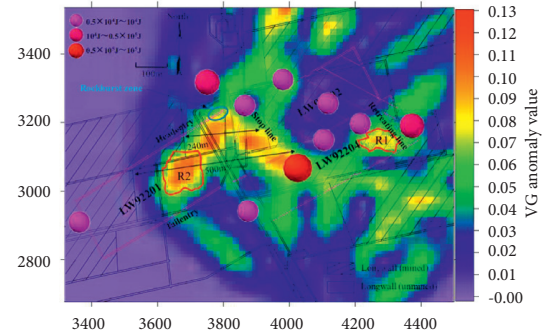

(c)

Figure 15: Tomography results at \#9 coal seam (microseismic events of January 2015) [113].

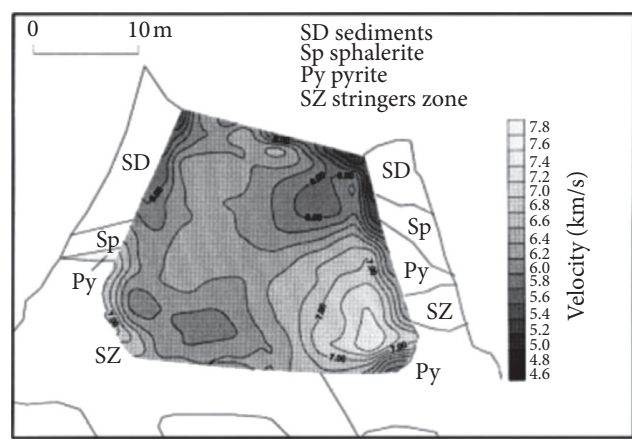

(a)

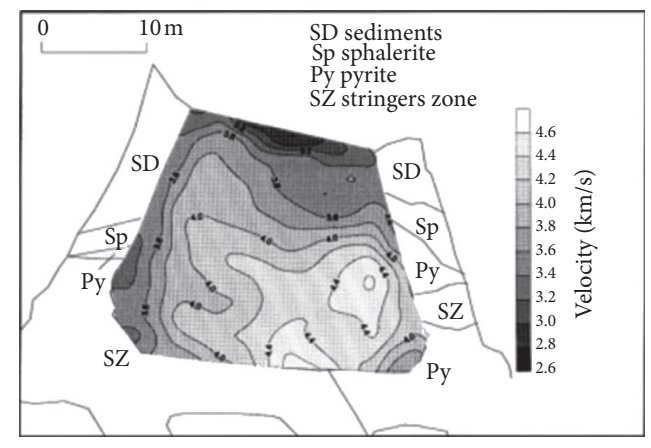

(b)

Figure 16: Tomograms of pillar A. P-wave tomogram (a) and S-wave tomogram (b) [121].

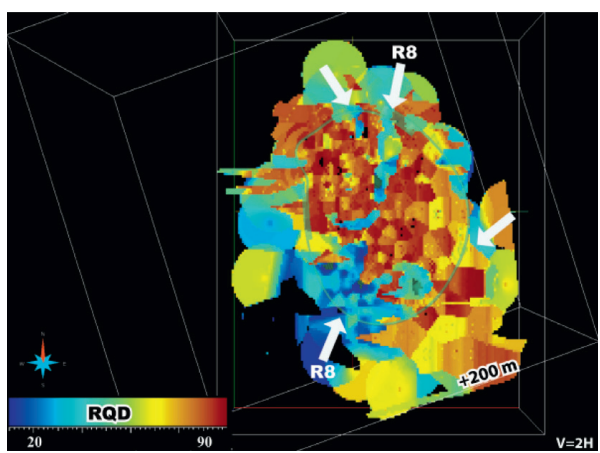

(a)

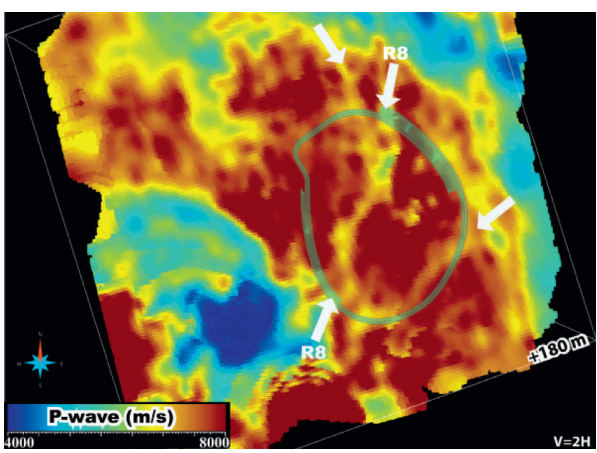

(b)

FIgure 17: Comparison of (a) RQD model and (b) P-wave velocity model in three-dimensional views [122].

evolution characteristics of mining-induced rock mass fractures as the seismic energy tends to refract around these low-velocity zones

\section{Concluding Remarks}

Under the combination of in situ stress field and mining activities, mining-induced stress concentrations caused by the redistribution of surrounding rock stress will lead to rock burst, spalling, and other failure types, which seriously hinders the safe and efficient ore production from deep mines. With the increase of mining depth year by year, injuries and fatalities caused by mining-induced stress in deep deposits are becoming more prominent. This review summarized the research in mining-induced stress, rock mechanics for mining engineering, and microseismic velocity tomography and its application in mining engineering.

Mining excavation activities will cause stress concentration during the stress redistribution process. The magnitude and orientation of stresses change depending on mining methods, geologic structures, advance rate, etc. Theory analysis, physical simulation, numerical simulation, and in situ measurement methods can be used to estimate or measure the mining-induced stresses. In situ measurement methods are divided into direct and indirect methods. 
Compared with these two methods, indirect methods show better potential in analysis of mining-induced stress in large scale. Due to the mining-induced stress redistribution, the surrounding rock will have differing failure modes, such as spalling, rock burst, and roof fall. These failure modes can be divided into relaxation and stress-driven failures. Rock mechanics under different stress paths can be used to analyze the mining-induced rock failure characteristics.

With the development of the science of seismology, microseismic monitoring technology has become a mature method for monitoring the failure of surrounding rock during mining. Parameters, such as energy index, b-values, and events rate, help us to understand the process of mininginduced stress accumulation, migration, surrounding rock fracturing or fault-slip, and rock mass structure instability, which can also be used for early warning and control for potential mining-induced hazards.

The application of microseismic monitoring technology, especially passive velocity tomography, can help to understand the instability process and response of miningdisturbed surrounding rock, which can be used for early warning of hazards and also improved ground control. Seismic tomography has been effective in detecting underground structures. According to the relationship between stress and velocity, it can be a better indicator of mining-induced stress variation. In recent decades, active and passive velocity tomographies have been successfully used in the field of mining engineering, which are validated by in situ stress measurement and numerical simulation. When comparing these two methods, microseismic passive velocity tomography shows good potential for studying the evolution of mining-induced stress, rock mass failure analysis, and mining-induced hazards at deep, large-scale mines. Ore body delineation and rock mass characterization can be carried out at the same time. However, microseismic passive velocity tomography result is not always successful and effective, so the accuracy and timeliness must be improved. Early warning of hazards based on microseismic passive velocity tomography should be improved accordingly. In recent years, artificial intelligence technology is growing vigorously, and it shows better potential in microseismic monitoring data analysis. The artificial intelligence technology can be used to pick events with low signal to noise ratio or buried in large events, which also can be used to improve the accuracy of arrival time picking. High-resolution event location methods and efficient inversion method should be developed. Comprehensive methods considering focal mechanism, b-value, energy index, events clustering characteristics, and tomography results also need to be developed at the same time. Characterizing of mining-induced fractures at a large scale is always a challenging problem. Traditional methods, such as borehole camera and borehole acoustic televiewer, can only observe the mining-induced fractures in small scale. As attenuation tomography is sensitive to the degree of fracture in the rock mass, so this technology will be a promising way to detect mining-induced fractures in mining engineering and other underground rock engineering.

\section{Data Availability}

The data used to support the findings of this study are included within the article.

\section{Conflicts of Interest}

The authors declare that there are no conflicts of interest.

\section{Acknowledgments}

The authors would like to thank Dr. Setareh Ghaychi Afrouz of Virginia Tech for her help in finding related papers. This work was funded by the NSFC-Shandong Joint Fund (U1806208) and State Key Laboratory of Nickel and Cobalt Resources Comprehensive Utilization, the Fundamental Research Fund for the Central Universities (N2001033), and China Scholarship Council (File no. 201906080107).

\section{References}

[1] H. Xie, F. Gao, and Y. Ju, "Research and development of rock mechanics in deep ground engineering," Chinese Journal of Rock Mechanics and Engineering, vol. 34, pp. 2161-2178, 2015.

[2] X. Zhao, "Basic theory and dvelopment trends of ultra-deep shaft construction," Metal Mine, vol. 47, pp. 1-10, 2018.

[3] M. F. Cai, D. L. Xue, and F. H. Ren, "Current status and development strategy of metal mines," Chinese Journal of Engineering, vol. 41, pp. 417-426, 2019.

[4] M. C. He, H. P. Xie, S. P. Peng, and Y. D. Jiang, "Study on rock mechanics in deep mining engineering," Chinese Journal of Rock Mechanics and Engineering, vol. 24, pp. 2803-2813, 2005.

[5] E. Hoek, Practical Rock Engineering, Evert Hoek Consulting Engineer Inc., North Vancouver, Canada, 2000.

[6] S. S. Peng, Coal Mine Ground Control, Society for Mining, Metallurgy \& Exploration Inc., Englewood, Co, USA, 2008.

[7] G. Xie and K. Yang, "Study of macro stress shell evolving characteristics of rock surrounding face," Chinese Journal of Rock Mechanics and Engineering, vol. 29, pp. 2676-2680, 2010.

[8] G. Xie and L. Wang, "Lithologic effect on the mechanical characteristics of mining-induced stress shell," Journal of China Coal Society, vol. 38, pp. 2-7, 2013.

[9] J. Zhang, "Mining-induced stress characteristics and fracture evolution law of over one kilometer deep Pingdingshan coal mine," Journal of China University of Mining and Technology, vol. 46, pp. 1041-1049, 2017.

[10] F. Luo, S. Cao, G. Li, and Y. Li, "Evolution of mine-induced stress concentration shell and stress relief body and its gas migration," Journal of Mining and Safety Engineering, vol. 35, pp. 155-162, 2018.

[11] J. Zheng, W. Ju, X. Zhao, J. Wu, S. Ren, P. Zhao et al., "Dynamic evolution characteristic on stope pressure in whole life cycle of stope," Journal of China Coal Society, vol. 44, pp. 995-1002, 2019.

[12] L. Jiang, Q. Wu, X. Li, and D. Nan, "Numerical simulation on coupling method between mining-induced stress and goaf compression," Journal of China Coal Society, vol. 42, pp. 1951-1959, 2017.

[13] P. F. Wang, G. R. Feng, J. L. Zhao, Y. P. Chugh, and Z. Wang, "Effect of longwall gob on distribution of mining-induced 
stress," Chinese Journal of Geotechnical Engineering, vol. 40, pp. 1237-1246, 2018.

[14] S. Majumder and S. Chakrabarty, "The vertical stress distribution in a coal side of a roadway-an elastic foundation approach," Mining Science and Technology, vol. 12, no. 3, pp. 233-240, 1991.

[15] S. Jayanthu, T. N. Singh, and D. P. Singh, "Stress distribution during extraction of pillars in a thick coal seam," Rock Mechanics and Rock Engineering, vol. 37, pp. 171-192, 2004.

[16] R. D. Caudle and G. B. Clark, Stresses Around Mine Openings in Some Simple Geologic Structures, Uinversity of Illinois Bulletin, Illionis, IL, USA, 1955.

[17] M. D. G. Salamon, "Elastic analysis of displacements and stresses induced by the mining of seam or reef deposits : part II : practical methods of determining displacement, strain and stress components from a given mining geometry," Journal of the South African Institute of Mining and Metallurgy, vol. 64, pp. 197-218, 1964.

[18] Z. Song, "Basic rules for stope overlying strata," Journal of Shandong Institute of Mining and Technology, vol. 1, pp. 12-25, 1979.

[19] C. Mark, Pillar Design Methods for Longwall Mining, US Department of the Interior, Bureau of Mines, Washington, DC, USA, 1990.

[20] C. Mark, "Analysis of longwall pillar stability (ALPS): an update," in Proceedings of the Workshop on Coal Pillar Mechanics and Design, pp. 238-249, US Department of the Interior, Bureau of Mines, Pittsburgh, PA, USA, January 1992.

[21] M. Qian, X. Miao, and J. Xu, "Theoretical study of key stratum in ground control," Journal of China Coal Society, vol. 21, pp. 225-230, 1996.

[22] M. Qian, P. Shi, and J. Xu, Mine Pressure and Ground Control, China University of Mining \& Technology Press, Beijing, China, 2003.

[23] K. A. Heasley, "The forgotten denominator, pillar loading," in Proceedings of the 4th North American Rock Mechanics Symposium, pp. 457-464, American Rock Mechanics Association, Seattle, WA, USA, July 2000.

[24] M. Rezaei, M. F. Hossaini, and A. Majdi, "Determination of longwall mining-induced stress using the strain energy method," Rock Mechanics and Rock Engineering, vol. 48, no. 6, pp. 2421-2433, 2015.

[25] M. Rezaei, "Forecasting the stress concentration coefficient around the mined panel using soft computing methodology," Engineering with Computers, vol. 35, no. 2, pp. 451-466, 2019.

[26] M. He, R. Huang, and J. Wang, Engineering Geology Numerical Method, China Science Publishing \& Media Ltd, Beijing, China, 2006.

[27] R. K. Sinha, D. S. Subrahmanyam, G. Shyam, and S. Sengupta, "Understanding the mining induced stresses by actual measurement and numerical modeling in a deep lead zinc mine," in Proceedings of the National Seminar on Innovative Practices in Rock Mechanics (IPRM-2014), Bengaluru, India, January 2014.

[28] M. Sepehri, Finite Element Analysis Model for Determination of In-Situ and Mining Induced Stresses as a Function of Two Different Mining Methods Used at Diavik Diamond Mine, University of Alberta, Edmonton, Canada, 2016.

[29] H. Li, Similar Simulation Test of Mine Pressure, China University of mining and Technology Press, Beijing, China, 1988.
[30] G. Li, S. Cao, F. Luo, Y. Li, and Y. Wei, "Research on mininginduced deformation and stress, insights from physical modeling and theoretical analysis," Arabian Journal of Geosciences, vol. 11, 2018a.

[31] Z.-1. Zhao and Z.-j. Wen, "Design and application of a mining-induced stress testing system," Geotechnical \& Geological Engineering, vol. 36, no. 3, pp. 1587-1596, 2018.

[32] M. F. Cai, Principle and Techniques of In-Situ Stress Measurement, Science Press, Beijing, China, 2000.

[33] H. Kang and J. Lin, "New development in geomechanics measurement and test technology of mine roadway surrounding rock," Coal Science and Technology, vol. 29, pp. 27-30, 2001.

[34] P. H. Lu, "Mining-induced stress measurement with hydraulic borehole pressure cells," in Proceedings of the 25th U.S. Symposium on Rock Mechanics (USRMS), pp. 204-211, Evanston, IL, USA, June 1984.

[35] R. P. Young and S. C. Maxwell, "Seismic characterization of a highly stressed rock mass using tomographic imaging and induced seismicity," Journal of Geophysical Research, vol. 97, pp. 361-373, 1992.

[36] E. Westman, "Characterization of structural integrity and stress state via seismic methods: a case study," in Proceedings of the 12th International Conference on Ground Control in Mining, S. S. Peng, Ed., West Virginia Univ., Morgantown, WV, USA, pp. 322-328, August 1993.

[37] E. G. Zahl, J. P. Dunford, A. Schillser, M. K. Larson, P. Pierce, and F. Jones, "Development of stress measurement techniques in bump-prone coal for safety decisions," in Proceedings of the 19th International Conference on Ground Control in Mining, pp. 101-111, Morgantown, WV, USA, August 1994.

[38] E. G. Zahl, J. P. Dunford, D. R. Tesarik, M. K. Larson, and J. Chan, "Development of stress measurements and instrument placement techniques for longwall coal," in Proceedings of the DC Rocks 2001-38th US Symposium on Rock Mechanics (USRMS), pp. 327-335, Washington, DC, USA, July 2001.

[39] X. Liu, E. Wang, X. He, Z. Liu, E. L. Zhao, and Y. Wang, "Electromagnetic radiation laws of the stress distribution in working face," Journal of China Coal Society, vol. 32, pp. 1019-1022, 2007.

[40] D. Song, E. Wang, X. He et al., "Use of electromagnetic radiation from fractures for mining-induced stress field assessment," Journal of Geophysics and Engineering, vol. 15, no. 4, pp. 1093-1103, 2018.

[41] Z.-h. Ouyang, C.-h. Li, W.-c. Xu, and H.-j. Li, "Measurements of in situ stress and mining-induced stress in Beiminghe iron mine of China," Journal of Central South University of Technology, vol. 16, no. 1, pp. 85-90, 2009.

[42] W. Xu, Studies on Monitoring Technology of Mining Space Surrounding Rock Stress and its Application, China University of Mining \& Technology, Xuzhou, China, 2012.

[43] C. Q. Ma, B. Q. Dai, and G. P. Qin, "Experimental study on kilometer-deep shaft working face advancing step and mining-induced stress distribution law," in Applied Mechanics and Materials, vol. 353-356, pp. 1422-1426, Trans Tech Publ, 2013.

[44] K. Soucek, P. Konicek, and P. Waclawik, "Experimental approach to measure stress and stress changes in rock ahead of longwall mining faces in Czech coal mines," in Proceedings of the 13th Coal Operators' Conference, pp. 115-123, Wollongong, Australia, February 2013. 
[45] T. Li, M. Cai, L. Sun, and Y. Zuo, "Inversion of mininginduced stress field and its application based on focal mechanism solution," Chinese Journal of Rock Mechanics and Engineering, vol. 35, pp. 1747-1753, 2016.

[46] X. Zhao, Deep Mining Induced Stress and Controlling Method at Hard Rock Deposits, Metallurgical Industry Press, Beijing, China, 2019.

[47] C. D. Martin, P. K. Kaiser, D. D. Tannant, and S. Yazici, "Index," La FA, Karthala, Paris, France, 1999.

[48] P. K. Kaiser, S. Yazici, and S. Maloney, "Mining-induced stress change and consequences of stress path on excavation stability-a case study," International Journal of Rock Mechanics and Mining Sciences, vol. 38, no. 2, pp. 167-180, 2001.

[49] P. K. Kaiser, M. S. Diederichs, C. D. Martin, J. Sharp, and W. Steiner, "Underground works in hard rock tunnelling and mining," in Proceedings of the ISRM international symposium. International Society for Rock Mechanics and Rock Engineering, Melbourne, Australia, November 2000.

[50] K. Larsson, Mining Induced Seismicity in Sweden, Luleå tekniska universitet, Lulea, Sweden, 2004.

[51] A. J. Mendecki, R. A. Lynch, and D. A. Malovichko, "Routine micro-seismic monitoring in mines," in Proceedings of the Australian Earthquake Engineering Soc., Annual Conference, pp. 1-33, Perth, Australia, November 2010.

[52] J. Zhou, Research on Evolution Mechanism of Rock Failure Based on Acoustic Emission and Microseismic Monitoring and its Application, Northeastern University, Boston, MA, USA, 2017.

[53] S. Li, M. Gao, X. Yang et al., "Numerical simulation of spatial distributions of mining-induced stress and fracture fields for three coal mining layouts," Journal of Rock Mechanics and Geotechnical Engineering, vol. 10, no. 5, pp. 907-913, 2018.

[54] G. A. Mendonça, M. S. Lana, and R. P. D. Figueiredo, "Influence of induced stresses by sublevel stopes in stability conditions of development openings in underground mines," Tecnologia em Metalurgia Materiais e Mineração, vol. 15, no. 2, pp. 159-166, 2018.

[55] Y. Zhao, T. Yang, M. Bohnhoff et al., "Study of the rock mass failure process and mechanisms during the transformation from open-pit to underground mining based on microseismic monitoring," Rock Mechanics and Rock Engineering, vol. 51, no. 5, pp. 1473-1493, 2018.

[56] T. Zhang, Q. Gan, Y. Zhao et al., "Investigations into mininginduced stress-fracture-seepage field coupling effect considering the response of key stratum and composite aquifer," Rock Mechanics and Rock Engineering, vol. 52, no. 10, pp. 4017-4031, 2019.

[57] F. Jiang, X. Luo, and S. Yang, "Study on microseismic monitoring for spatial structure of overlying strata and mining pressure field in longwall face," Chinese Journal of Geotechnical Engineering, vol. 25, pp. 23-25, 2003.

[58] S. Li, X. Yin, W. Zheng, and C. Trifu, "Research of multichannel microseismic monitoring system and its application to Fankou lead-zinc mine," Chinese Journal of Rock Mechanics and Engineering, vol. 24, pp. 2048-2053, 2005.

[59] Z. Yang, R. Yu, R. Guo, and L. Wang, "Research of mining based on microseismic monitoring technology in high-stress area," Chinese Journal of Rock Mechanics and Engineering, vol. 28, pp. 3632-3638, 2009.

[60] Y. Xia, H. Lan, D. Mao, and J. Pan, "Study of the lead abutment pressure distribution base on microseismic monitoring," Journal of China University of Mining \& Technology, vol. 40, pp. 868-873, 2011.

[61] P. Zhang, T. Yang, C. Zheng, Q. Yu, H. Liu, and P. Wang, "Analysis of surrounding rock stability based on mining stress field and microseismicity," Journal of China Coal Society, vol. 38, pp. 183-188, 2013.

[62] S. Wang, D. Mao, J. Pan, and H. Lan, "Measurement on the whole process of abutment pressure evolution and microseismic activities at the lateral strata of goaf," Journal of China Coal Society, vol. 40, pp. 2772-2779, 2015.

[63] Z. Ouyang, L. Kong, Q. Qi, H. Zhang, S. Li, and S. Zhao, "Self-shocking microseismic monitoring technology and its application in prediction of dynamic pressure in shallow coal seam," Journal of China Coal Society, vol. 43, pp. 44-51, 2018.

[64] D. Liu, C. Liu, F. Zhang, Y. Liu, and B. Guo, "Building and application of microseismic monitoring system based on stress analysis," Journal of Mining and Safety Engineering, vol. 33, pp. 932-938, 2016.

[65] P. Swanson, W. Koontz, and J. Abshire, "Seismic network operations at a deep underground coal mining district in western Colorado (USA)," Controlling Seismic Hazard and Sustainable Development of Deep Mines, vol. 2, 2009.

[66] M. Boltz, D. Chambers, and D. Hanson, "Evaluating seismicity at underground coal mines using temporary surface geophone deployments," in Proceedings of the 52nd US Rock Mechanics/Geomechanics Symposium, OnePetro, Seattle, WA, USA, June 2018.

[67] M. Ge, "Efficient mine microseismic monitoring," International Journal of Coal Geology, vol. 64, no. 1-2, pp. 44-56, 2005.

[68] Esg Solutions, How-A-Microseismic-System-Works, ESG solutions, Kingston, Canada, 2020.

[69] F. J. M. Moreno, Detection and Characterization of Karstic Caves: Integration of Geological and Geophysical Techniques, Universidad de Granada, Granada, Spain, 2015.

[70] P. V. Sharma, Geophysical Methods in Geology, Springer, Berlin, Germany, 1985.

[71] R. D. Lama and V. S. Vutukuri, Handbook on Mechanical Properties of Rocks-Testing Techniques and Results-Volume Ii, Trans Tech Publications, Bach, Switzerland, 1978.

[72] S. C. Maxwell and R. P. Young, "Sequential velocity imaging and microseismic monitoring of mining-induced stress change," Pure and Applied Geophysics PAGEOPH, vol. 139, no. 3-4, pp. 421-447, 1992.

[73] E. Westman, "Passive seismic imaging for determination of the longwall rear abutment location," in Proceedings of the 31st International Conference on Ground Control in Mining, Morgantown, WV, USA, August 2012.

[74] B. Gutenberg, "Wave vd," Geophysical Journal International, vol. 2, no. 4, pp. 348-352, 1959.

[75] A. Nur, "Effects of stress on velocity anisotropy in rocks with cracks," Journal of Geophysical Research, vol. 76, no. 8, pp. 2022-2034, 1971.

[76] T. Engelder and R. Plumb, "Changes in in situ ultrasonic properties of rock on strain relaxation," International Journal of Rock Mechanics and Mining Science \& Geomechanics Abstracts, vol. 21, no. 2, pp. 75-82, 1984.

[77] C. M. Sayers and M. Kachanov, "Microcrack-induced elastic wave anisotropy of brittle rocks," Journal of Geophysical Research: Solid Earth, vol. 100, no. B3, pp. 4149-4156, 1995.

[78] X. Huang, D. R. Burns, and M. N. Toksoz, The Effect of Stresses on the Sound Velocity in Rocks: Theory of Acoustoelasticity and Experimental Measurements, Massachusetts Institute of Technology, Cambridge, MA, USA, 2001.

[79] W. W. Wepfer and N. I. Christensen, "A seismic velocityconfining pressure relation, with applications," International Journal of Rock Mechanics and Mining Science \& Geomechanics Abstracts, vol. 28, no. 5, pp. 451-456, 1991. 
[80] R. J. Greenfield and E. K. Graham, “Application of a simple relation for describing wave velocity as a function of pressure in rocks containing microcracks," Journal of Geophysical Research: Solid Earth, vol. 101, no. B3, pp. 5643-5652, 1996.

[81] D. Freund, "Ultrasonic compressional and shear velocities in dry clastic rocks as a function of porosity, clay content, and confining pressure," Geophysical Journal International, vol. 108, no. 1, pp. 125-135, 1992.

[82] A. Khaksar, C. M. Griffiths, and C. McCann, "Compressional- and shear-wave velocities as a function of confining stress in dry sandstones," Geophysical Prospecting, vol. 47, no. 4, pp. 487-508, 1999.

[83] S. Gong, Research and Application of Using Mine Tremor Velocity Tomography to Forecast Rockburst Danger in Coal Mine, China University of Mining \& Technology, Xuzhou, China, 2010.

[84] G. Li, Study of the Synchronized Correlation between Stress and Ultrasonic Velocity of sandstone in Real Time, Lanzhou University, Lanzhou, China, 2013.

[85] J. Radon, "über die bestimmung von funktionen durch ihre integralwerte längs gewisser mannigfaltigkeiten," Classic papers in modern diagnostic radiology, vol. 5, p. 21, 1917.

[86] S. R. Deans, The Radon Transform and Some of its Applications, Dover Publications, Mineola, NY, USA, 2007.

[87] K. D. Luxbacher, Four-Dimensional Passive Velocity Tomography of a Longwall Panel, Virginia Tech, Blacksburg, VA, USA, 2005.

[88] K. Luxbacher, E. Westman, P. Swanson, and M. Karfakis, "Three-dimensional time-lapse velocity tomography of an underground longwall panel," International Journal of Rock Mechanics and Mining Sciences, vol. 45, no. 4, pp. 478-485, 2008.

[89] M. J. Jackson and D. R. Tweeton, MIGRATOM: Geophysical Tomography Using Wavefront Migration and Fuzzy Constraints, U.S. Dept. of Interior, Bureau of Mines, Washington, DC, USA, 1994.

[90] H. Zhang and C. H. Thurber, "Double-difference tomography: the method and its application to the Hayward fault, California," Bulletin of the Seismological Society of America, vol. 93, no. 5, pp. 1875-1889, 2003.

[91] H. Zhang and C. Thurber, "Development and applications of double-difference seismic tomography," Pure and Applied Geophysics, vol. 163, no. 2-3, pp. 373-403, 2006.

[92] E. Westman, K. Luxbacher, and S. Schafrik, "Passive seismic tomography for three-dimensional time-lapse imaging of mining-induced rock mass changes," The Leading Edge, vol. 31, no. 3, pp. 338-345, 2012.

[93] J. Qian, H. Zhang, and E. Westman, "New time-lapse seismic tomographic scheme based on double-difference tomography and its application in monitoring temporal velocity variations caused by underground coal mining," Geophysical Journal International, vol. 215, no. 3, pp. 2093-2104, 2018.

[94] G. Nolet, "Seismic wave propagation and seismic tomography," in Seismic Tomography Springer, Berlin, Germany, 1987.

[95] S. C. Maxwell and R. P. Young, "A comparison between controlled source and passive source seismic velocity images," Bulletin of the Seismological Society of America, vol. 83, pp. 1813-1834, 1993.

[96] H. He, L. Dou, X. Li, Q. Qiao, T. Chen, and S. Gong, "Active velocity tomography for assessing rock burst hazards in a kilometer deep mine," Mining Science and Technology, vol. 21, no. 5, pp. 673-676, 2011.
[97] A. M. Baig, K. Bosman, and T. Urbancic, "Temporal changes in stress state imaged through seismic tomography," in Proceedings of the 8th International Conference on Deep and High Stress Mining, pp. 269-273, Perth, Australia, January 2017.

[98] X. Ma, E. Westman, F. Malek, and M. Yao, "Stress redistribution monitoring using passive seismic tomography at a deep nickel mine," Rock Mechanics and Rock Engineering, vol. 52, no. 10, pp. 3909-3919, 2019.

[99] A. Körmendi, T. Bodoky, L. Hermann, L. Dianiska, and T. Kalman, Geophysical Prospecting, vol. 34, no. 7, pp. 1022-1037, 1986.

[100] X. Ma, E. C. Westman, B. P. Fahrman, and D. Thibodeau, "Imaging of temporal stress redistribution due to triggered seismicity at a deep nickel mine," Geomechanics for Energy and the Environment, vol. 5, pp. 55-64, 2016.

[101] E. C. Westman, M. M. Foss, and E. M. Williams, "Comparison of stress distribution images generated with $\mathrm{P}, \mathrm{SH}$, and $\mathrm{SV}$ velocity tomograms," in Proceedings of the 1994 SEG Annual Meeting, pp. 544-546, Los Angeles, CA, USA, October 1994.

[102] M. J. Friedel, M. J. Jackson, D. F. Scott, T. J. Williams, and M. S. Olson, "3-D tomographic imaging of anomalous conditions in a deep silver mine," Journal of Applied Geophysics, vol. 34, no. 1, pp. 1-21, 1995.

[103] X. Ma, Passive Seismic Tomography and Seismicity Hazard Analysis in Deep Underground Mines, Virginia Polytechnic Institute and State University, Blacksburg, VA, USA, 2014.

[104] Z. Wang, X. Li, D. Zhao, X. Shang, and L. Dong, "Time-lapse seismic tomography of an underground mining zone," International Journal of Rock Mechanics and Mining Sciences, vol. 107, pp. 136-149, 2018b.

[105] X. Ma, E. Westman, D. Counter, F. Malek, and B. Slaker, "Passive seismic imaging of stress evolution with mining-induced seismicity at hard-rock deep mines," Rock Mechanics and Rock Engineering, vol. 53, no. 6, pp. 2789-2804, 2020.

[106] E. C. Westman and K. Y. Haramy, "Seismic tomography to map hazards ahead of the longwall face," Mining Engineering, vol. 48, 1996.

[107] A. Lurka, "Location of high seismic activity zones and seismic hazard assessment in Zabrze Bielszowice coal mine using passive tomography," Journal of China University of Mining and Technology, vol. 18, no. 2, pp. 177-181, 2008.

[108] E. Westman and K. Luxbacher, "Seismic tomography, an ideal but immature tool for coal bump prediction," in Proceedings of the 27th International Conference on Ground Control in Mining, pp. 87-90, Morgantown, WV, USA, 2008.

[109] L. M. Dou, W. Cai, S. Y. Gong, R. J. Han, and J. Liu, "Dynamic risk assessment of rock burst based on the technology of seismic computed tomography detection," Journal of China Coal Society, vol. 39, pp. 238-244, 2014.

[110] J. Dubiński and J. Dworak, "Recognition of the zones of seismic hazard in polish coal mines by using a seismic method," Pure and Applied Geophysics PAGEOPH, vol. 129, pp. 609-617, 1989.

[111] G. Mutke, A. Lurka, and J. Dubiński, "Seismic monitoring and rock burst hazard assessment in deep polish coal mines-case study of rock burst on april 16, 2008 in WujekSlask coal mine," in Proceedings of the 7th International Symposium on Rockburst and Seismicity in Mines (RASiM 7): Controlling Seismic Hazard and Sustainable Development of Deep Mines. CA Tang, pp. 1413-1424, Rinton Press, Dalian, China, August 2009.

[112] S.-Y. Gong, J. Li, F. Ju, and L.-M. Y. Dou, "Passive seismic tomography for rockburst risk identification based on 
adaptive-grid method," Tunnelling and Underground Space Technology, vol. 86, pp. 198-208, 2019.

[113] J. Li, S.-Y. Gong, J. He et al., "Spatio-temporal assessments of rockburst hazard combining b values and seismic tomography," Acta Geophysica, vol. 65, no. 1, pp. 77-88, 2017.

[114] S. G. Afrouz, E. C. Westman, K. K. Dehn, B. Weston, and D. Luxbacher, "A conceptual protocol for integrating multiple parameters for risk assessment due to induced seismicity in a deep mine," in Proceedings of the 54th US Rock Mechanics/Geomechanics Symposium, Golden, CO, USA, June 2020.

[115] C. Cosma, "Determination of rock mass quality by the crosshole seismic method," Bulletin of rockmass quality by the crosshole seismic method, vol. 26, pp. 219-225, 1982.

[116] T. Inazaki and Y. Takahashi, "Evaluation of rock mass quality utilizing seismic tomography," in Proceedings of the 6th ISRM Congress, Monteral, Canada, September 1987.

[117] I. L. Meglis, T. Chow, C. D. Martin, and R. P. Young, "Assessing in situ microcrack damage using ultrasonic velocity tomography," International Journal of Rock Mechanics and Mining Sciences, vol. 42, no. 1, pp. 25-34, 2005.

[118] N. N. Melnikov, S. P. Mesyats, S. P. Ostapenko et al., "Investigation of disturbed rock zones in open-pit mine walls by seismic tomography," Key Engineering Materials, vol. 755, pp. 147-152, 2017.

[119] B. C. Dyer and A. Fawcett, "The use of tomographic imaging in mineral exploration," International Journal of Rock Mechanics and Mining Science \& Geomechanics Abstracts, vol. 3, p. 225A, 1995.

[120] S. Peng, B. Ling, and S. Liu, "Application of seismic tomography in longwall top-coal caving face," Chinese Journal of Rock Mechanics and Engineering, vol. 21, pp. 1786-1790, 2002.

[121] X. Luo, P. Hatherly, and G. Fallon, "Seismic tomographic determination of ore boundaries at scuddles mine in western Australia," CSIRO Research Review, pp. 154-156, 1999.

[122] A. Malehmir, A. Tryggvason, C. Wijns et al., "Why 3d seismic data are an asset for exploration and mine planning? velocity tomography of weakness zones in the kevitsa Ni-Cu-PGE mine, northern Finland," Geophysics, vol. 83, no. 2, pp. B33-B46, 2018. 